\title{
STP/TAMU/INL Collaboration Update: LWRS Risk-Informed Safety Margin Characterization (RISMC) Lead
}

Hongbin Zhang, Ronaldo Szilard

February 2018

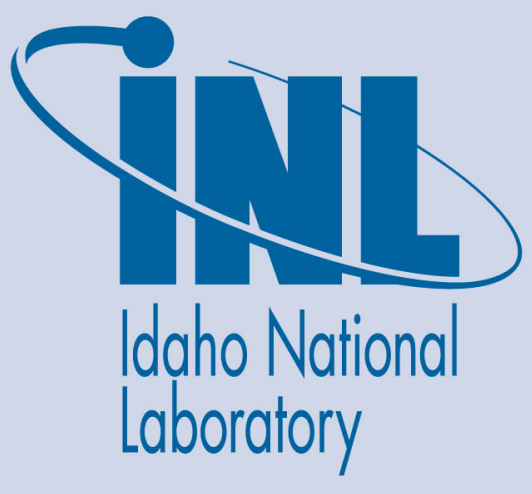

The INL is a U.S. Department of Energy National Laboratory operated by Battelle Energy Alliance 


\section{STP/TAMU/INL Collaboration Update: LWRS Risk- Informed Safety Margin Characterization (RISMC) Lead}

Hongbin Zhang, Ronaldo Szilard

February 2018

Idaho National Laboratory Idaho Falls, Idaho 83415

http://www.inl.gov

Prepared for the

U.S. Department of Energy

Under DOE Idaho Operations Office

Contract DE-AC07-05ID14517 


\section{STP/TAMU/INL Collaboration Update}

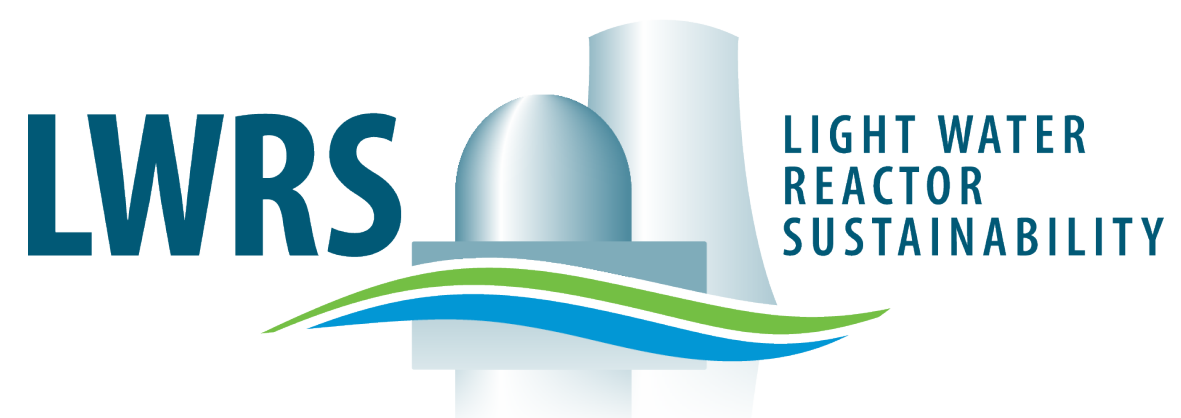

Ronaldo Szilard

LIGHT WATER

REACTOR

SUSTAINABILITY
LWRS Risk-Informed

Safety Margin Characterization (RISMC) Lead

South Texas Project NPP, Bay City, TX

February 14, 2018 


\section{STP/TAMU/INL Collaboration Meeting Objectives}

- Present a preliminary RISMC model, including plant model interfaces for Best Estimate Plus Uncertainty Loss-Of-Coolant Accident analysis using riskinformed analysis tools. Analysis results for a coupled core design, fuel/clad and systems analysis framework (LOTUS) will be presented for existing baseline codes (RELAP5-3D, FRAPCON) to Large Break Loss-Of-Coolant Accident scenarios

- Discuss applications of the Risk-Informed Safety Margin Characterization (RISMC) toolkit to relevant PWR emerging issues such as Accident Tolerant Fuel, FLEX, Resilient NPP designs, 10 CFR 50.69, etc.

- STP Feedback 


\begin{tabular}{|c|c|c|}
\hline TIME & TOPIC & PRESENTER \\
\hline $13: 00-13: 30$ & $\begin{array}{l}\text { Meeting Objectives and LWRS Program RISMC Pathway } \\
\text { Overview }\end{array}$ & Ronaldo Szilard (INL) \\
\hline $13: 30-14: 00$ & $\begin{array}{l}\text { Risk-Informed Methods and Tools for Core Design and Safety } \\
\text { Analysis }\end{array}$ & Carlo Parisi (INL) \\
\hline $14: 00-14: 30$ & Generic PWR Plant Model Based on STP & Kaleb Neptune (TAMU) \\
\hline $14: 30-15: 00$ & $\begin{array}{l}\text { Application of the LOTUS-Baseline Framework to a Generic } \\
\text { PWR Plant Model Based on STP for LB-LOCA with respect to } \\
\text { the NRC Proposed } 10 \text { CFR 50.46c Rulemaking }\end{array}$ & Hongbin Zhang (INL) \\
\hline $15: 00-15: 30$ & $\begin{array}{l}\text { Integrated Risk Evaluation Model (IREM) and Risk-Informed } \\
\text { Applications }\end{array}$ & Hongbin Zhang (INL) \\
\hline $15: 30-16: 00$ & $\begin{array}{l}\text { Collaboration Discussions - Brainstorming on Developing } \\
\text { Pilot Projects }\end{array}$ & All \\
\hline $16: 00$ & Adjourn & \\
\hline
\end{tabular}


LWRS (1)

Risk-Informed Safety
Margin Characterization

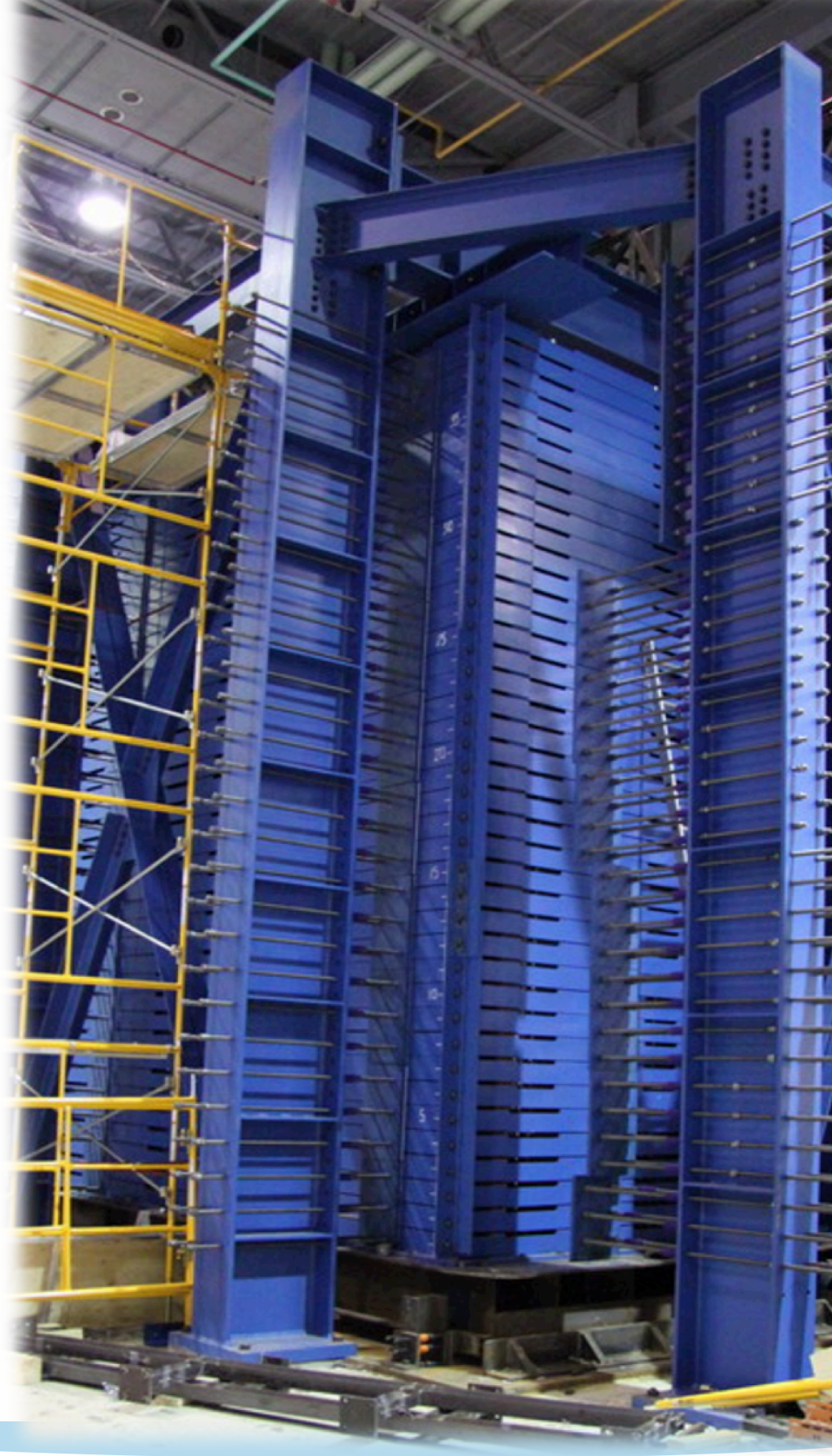




\section{IWRS Risk-Informed Safety Margin Characterization

- Inform decisions for risk-informed margin management to support improved economics, reliability, and sustain safety of current NPPs

\section{- RISMC Goals}

1. Develop and demonstrate a risk-assessment method coupled to safety margin quantification that can be used by decision makers as part of their margin recovery strategies

2. Create an advanced "RISMC toolkit" that enables more accurate representation (e.g., reduce conservatisms) of NPP safety margins

3. Risk-Informed analysis of realistic, relevant industry problems, with accurate representation of margins for the long term benefit of nuclear assets.

\section{- Strategy:}

- Develop industry application demonstrations in collaboration with the nuclear industry;

- Align demonstrations with RISMC methods and tools capabilities;

- Follow existing industry application structure, starting with existing (legacy codes) which will be replaced with advanced tools as they become available.

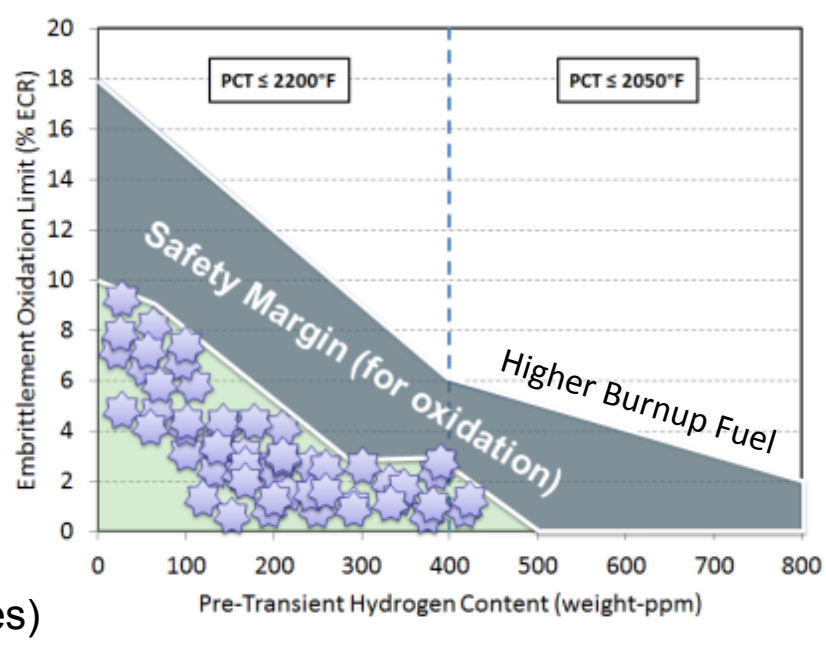




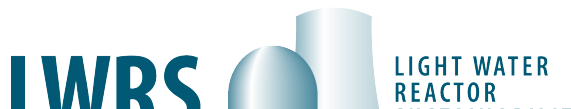

through Realistic Demonstrations

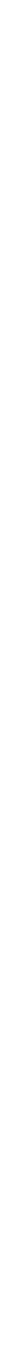




\section{LWRS (D) \\ RISMC Margin Quantification and Risk Assessment Paradigm}

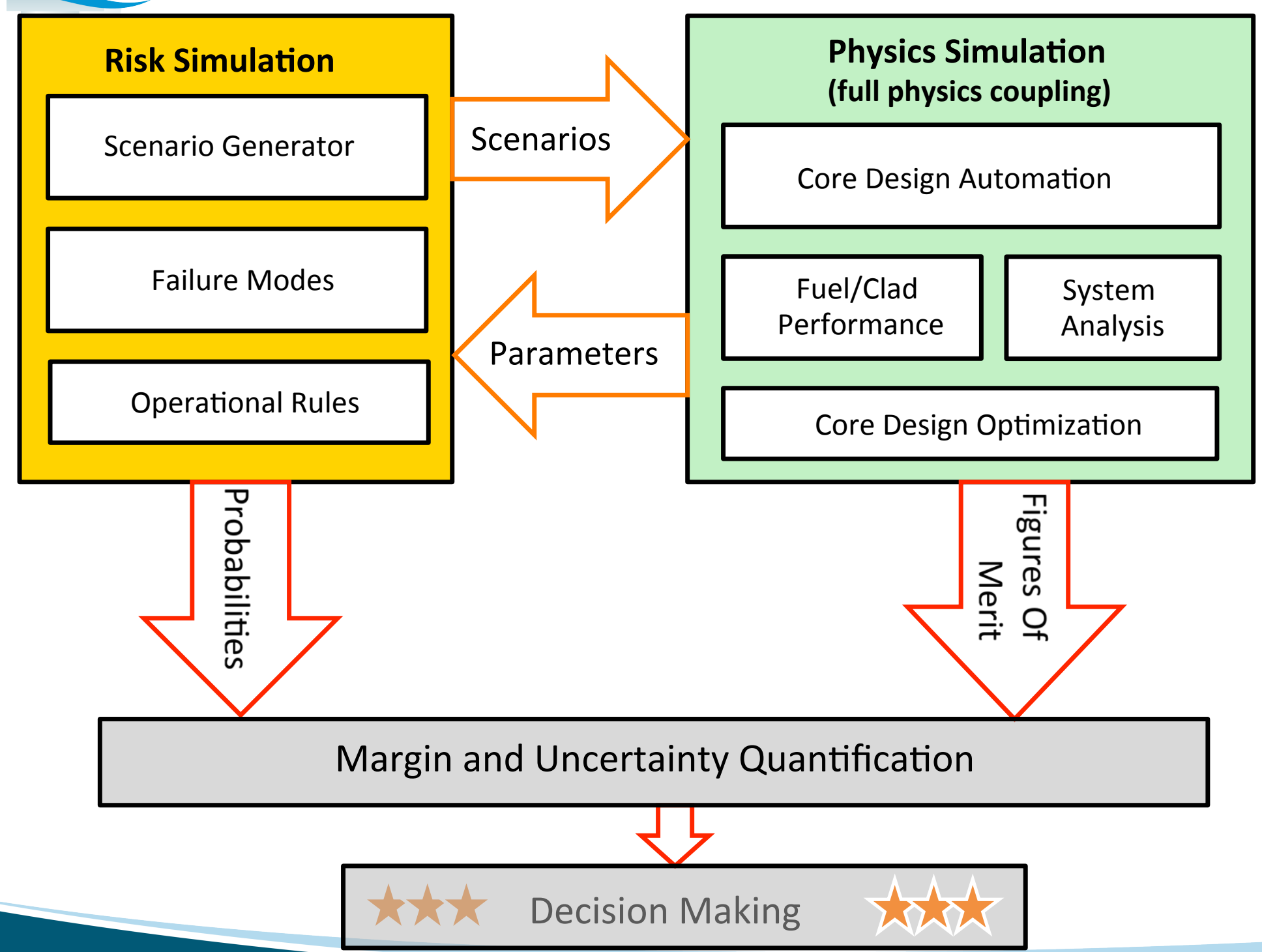




\section{LWRS N}

- Reverse thinking from 'traditional' approach, i.e., analyze the problem from a plant/systems level -> Core -> Component

- Leverage RISMC methods and tools + 10CFR 50.69 + FLEX to provide flexibility to reduce costs and improve plant operations \& safety margins
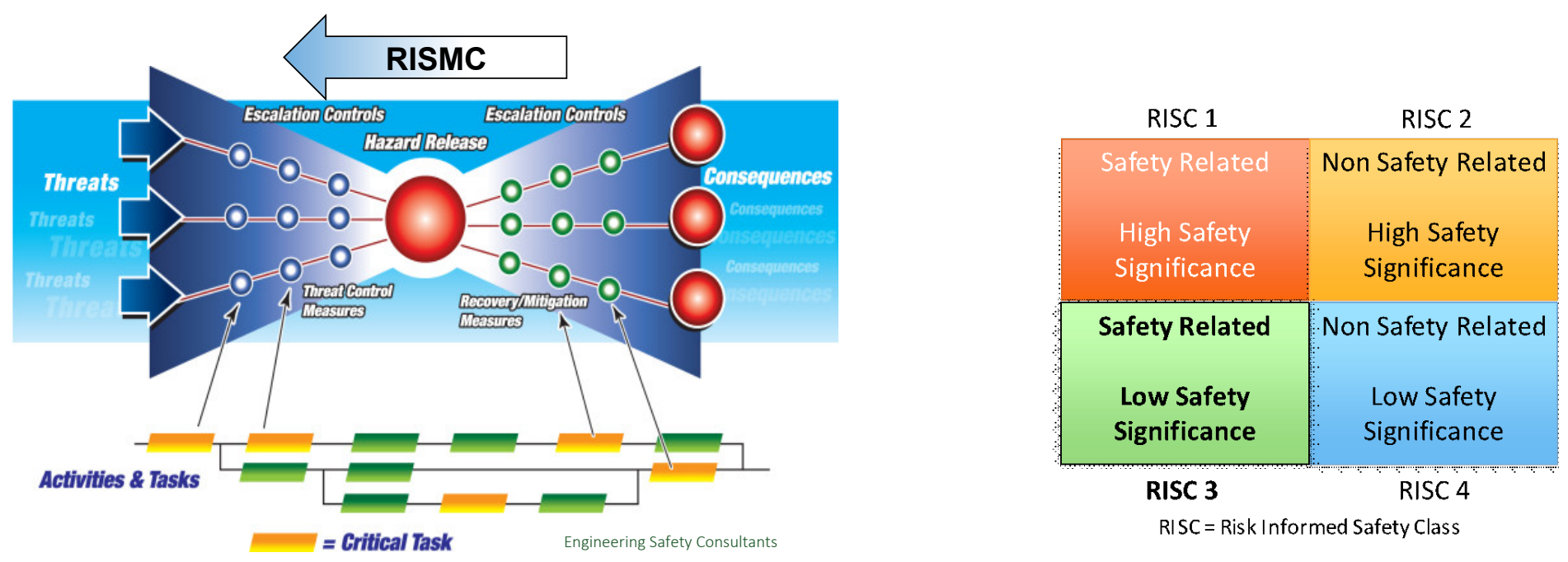


\section{Risk Informed Methods \& Tools for Core Design and Safety Analysis}

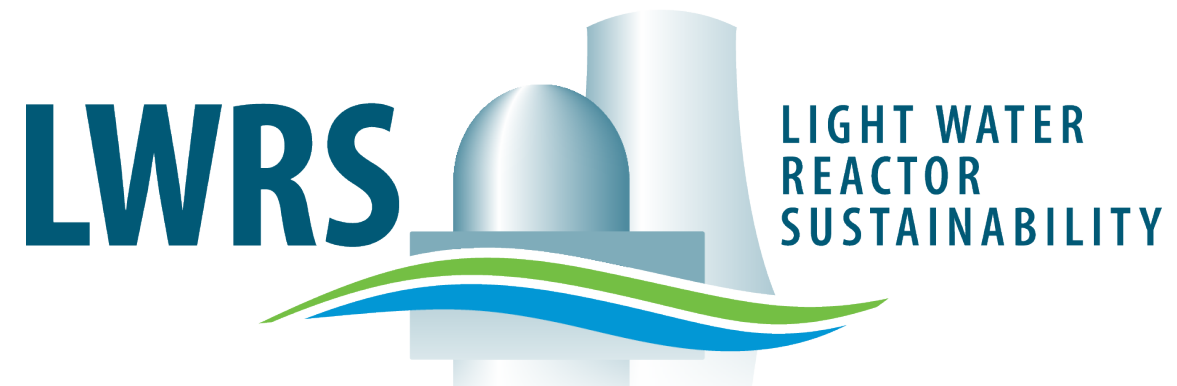

Carlo Parisi

REACTOR

SUSTAINABILITY INL

South Texas Project NPP, Bay City, TX February 14, 2018

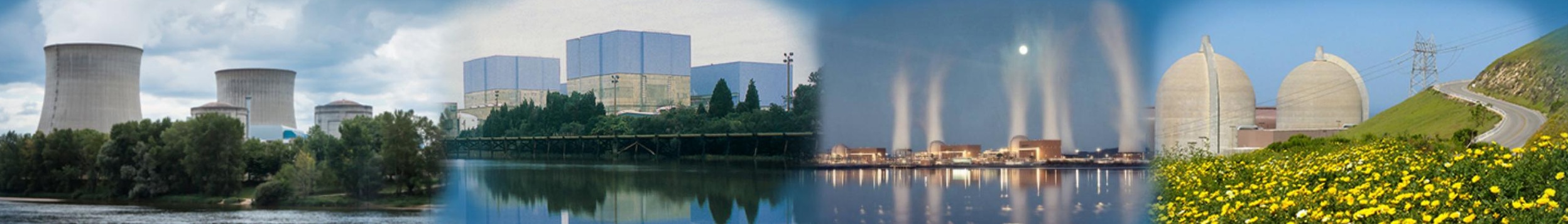




\section{LWRS_D}

- RISMC Overview

- Examples of RISMC activities \& possible STP collaborations

- BEPU + PRA

- Accident Tolerant Fuel Evaluation

- 10CFR50.69

- Multi-Unit simulation 


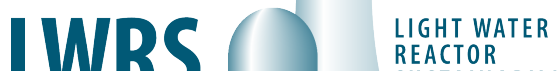 \\ RISMC Overview}

- US DOE Light Water Reactor Sustainability Program (LWRS) - RiskInformed Margin Characterization (RISMC) is a multi-years effort led by INL for better characterize the safety margins of the existing US LWR fleet

- Ultimate goal: increase LWR economics and reliability, sustain safety

- INL working on developing new:

- Tools (e.g.: RAVEN, MOOSE tools)

- Data

- Methods 
- What does it means Risk-Informed Margin Characterization?

- Develop Risk-Assessment method coupled to safety margins

\section{quantification}

- Integration of PRA and deterministic methods

- Highest level of knowledge for a safety analyst / NPP operator

\begin{tabular}{|c|c|c|c|}
\hline Option & Computer Code & $\begin{array}{c}\text { Availability of } \\
\text { Systems }\end{array}$ & $\begin{array}{c}\text { Initial and Boundary } \\
\text { Conditions }\end{array}$ \\
\hline 1) CONSERVATIVE & Conservative & $\begin{array}{c}\text { Conservative } \\
\text { Assumptions }\end{array}$ & $\begin{array}{c}\text { Conservative Input } \\
\text { Data }\end{array}$ \\
\hline 2) COMBINED & Best Estimate & $\begin{array}{c}\text { Conservative } \\
\text { Assumptions }\end{array}$ & $\begin{array}{c}\text { Conservative Input } \\
\text { Data }\end{array}$ \\
\hline 3) BEST ESTIMATE & Best Estimate & $\begin{array}{c}\text { Conservative } \\
\text { Assumptions }\end{array}$ & $\begin{array}{c}\text { Realistic }+ \\
\text { Uncertainty }\end{array}$ \\
\hline 4) RISK INFORMED & Best Estimate & Derived from PRA & $\begin{array}{c}\text { Realistic }+ \\
\text { Uncertainty }\end{array}$ \\
\hline
\end{tabular}

[IAEA, SSG-2, 2009] 


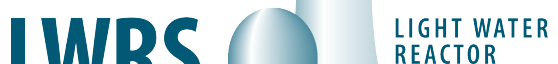

- Can we today pursue a RISMC approach?

- INL Tools, e.g.:

- RELAP5-3D $\rightarrow$ System TH analysis + 3D NK

- PHISICS $\rightarrow$ 3D NK + Burnup analysis

- SAPHIRE $\rightarrow$ Static PRA

- RAVEN \& EMRALD $\rightarrow$ Dynamic PRA

- RAVEN $\rightarrow$ UQ

- NEUTRINO $\rightarrow$ 3D Flooding

- MASTODON $\rightarrow$ Seismic analysis

- Data: INL RELAP5-3D and PRA database for US LWRs

- Computational power: INL Falcon Supercomputer (34,992 cores/121 TB memory / 1.087 Pflops $\left(10^{15}\right)$ LINPACK rating

- Methodologies: coupling of different tools tested for different industrial problems (LOCA, External events, etc.) 


\section{LWRS A RISMC activities}

- ECCS LOCA evaluation: 4-loop Westinghouse NPP, similar to STP (FY17)

- Coupling of RELAP5-3D/PHISICS/FRAP/ RAVEN

- LOCA analysis using realistic BIC $\rightarrow$ from detailed fuel cycle simulations (HELLO core)

- Evaluation of clad degradation / $\mathrm{H}_{2}$ generation for high burnup fuel (10CFR50.46 revised rule)
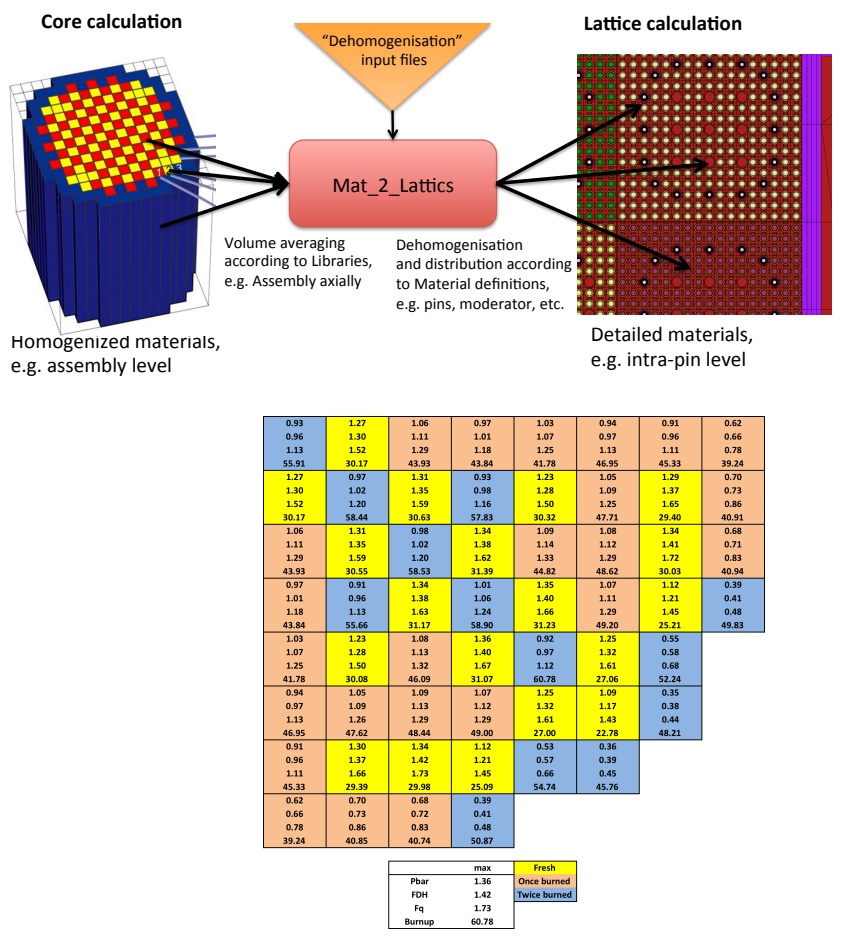

EOC power distribution

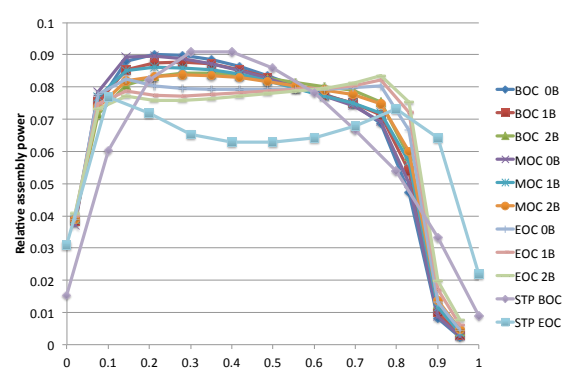




\section{LWRS ( RISMC activities}

- External Events simulations: achieving a fully integrated Deterministic + Probabilistic NPP Safety Analysis of External Events (BEPU + PRA)

- Effects of EQ on NPP using advanced seismic analyses [LS-DYNA \& MASTODON]

- NPP flooding scenarios caused by Earthquakes [NEUTRINO]

- NPP primary circuit + part of BOP dynamics [RELAP5-3D]

- Perform Uncertainty Quantification [RAVEN]

- Evaluate risk of scenarios using Dynamic PRA analysis [EMRALD]
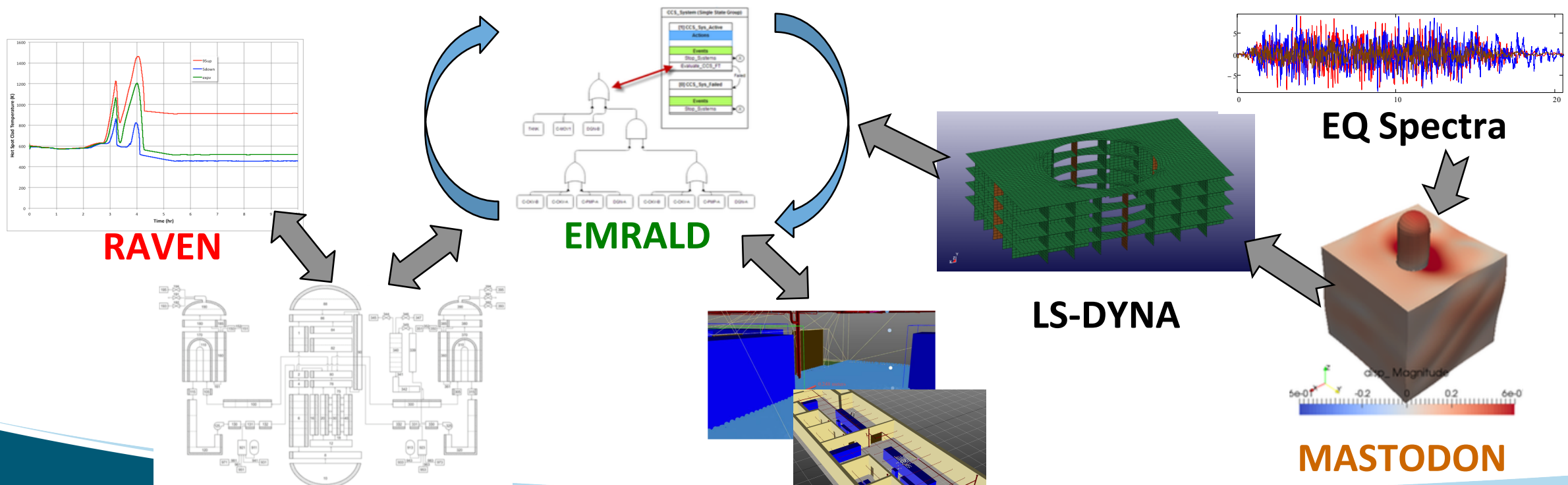


\section{LWRS D RISMC activities}
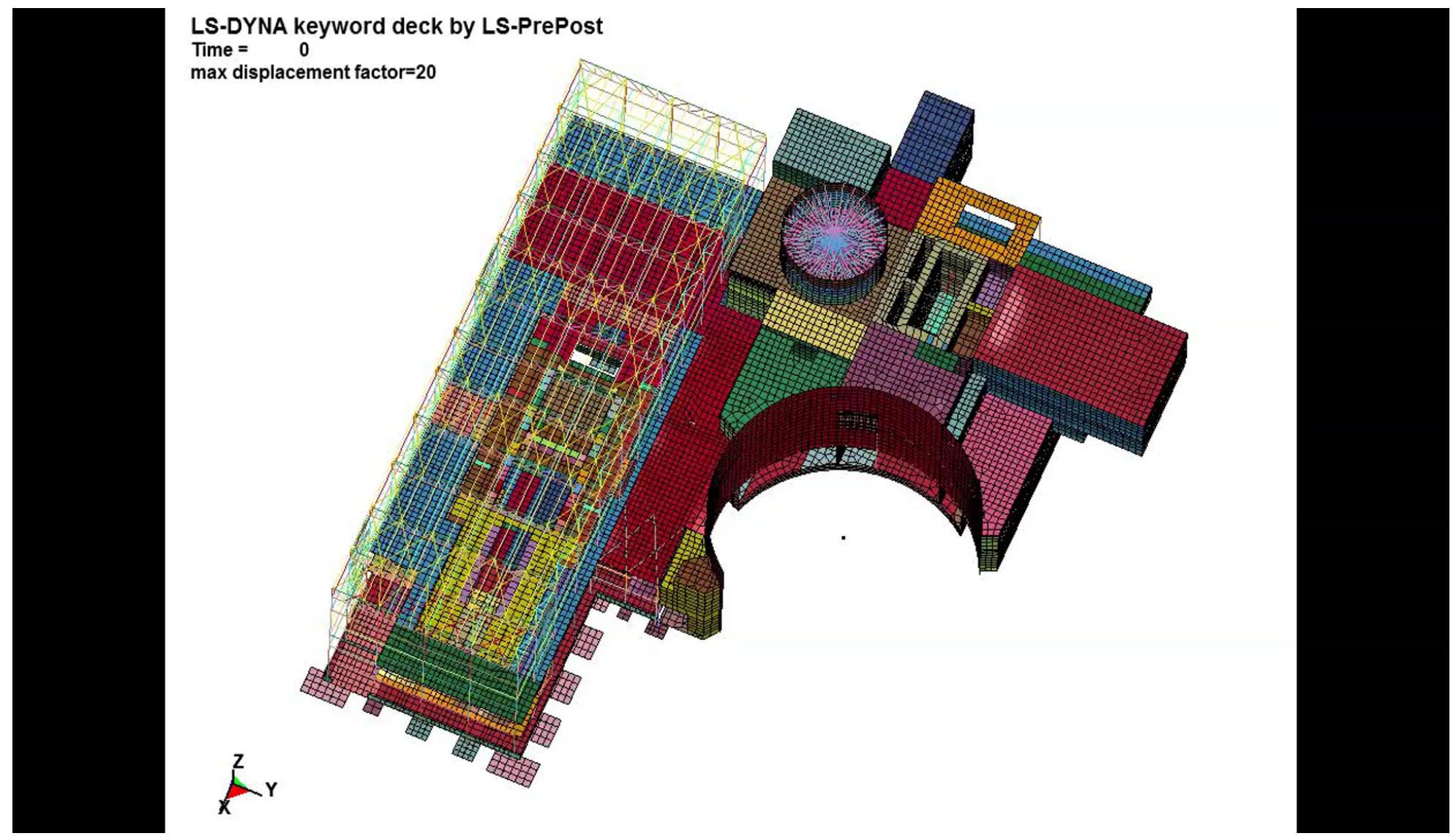

Multi-scale \& Multi-physics + Rilsk-Informed Analysis decrease conservatism, identify new risks 


\section{LWRS N}

- INL Tools (RELAP5-3D/RAVEN) allow performing Best-Estimate plus Uncertainty (BEPU) coupled to Probabilistic Risk Analysis (PRA)

- E.g.: analysis of a SBO sequence for a 3-loops Westinghouse PWR

- Development \& validation of a RELAP5-3D model

- Development of Phenomena Identification and Ranking Table (PIRT)

- Application of UQ method [e.g., non-parametric statistics (Wilks)]

- Coupling to dynamic PRA 


\section{LWRS A}

- PIRT for Mitigated-LTSBO

- Identify Important TH phenomena influencing the PCT, e.g.:

- NC in primary loop

- Secondary Side Mass Inventory loss through SG SRV/ PORV

- Primary Side Mass Inventory loss through MCP seal PRZ SRV/PORV

- Heat Transfer between primary/secondary system

- Preparing a (partial) list of RELAP5-3D input parameters perturbed by RAVEN code:

- Decay power

- MCP Seal LOCA break area

- Core Pressure losses

- Valves flow areas

- Heat Exchange multiplier 


\section{LWRS (}

- Selected Input parameters to be perturbed using Monte Carlo sampler + assigned PDF

- Final PCT UQ calculation, different approaches possible:

- MC (500-1000 calculations) $\rightarrow$ brute force

- Tolerance Limits (Wilks` formula)

- 59 / 93 / 124 / 153 calculations (first, second, etc order statistics)

- Train a meta-model, then perform MC on meta-model

- Use of RAVEN code "BasicStatistics" function

\begin{tabular}{|c|c|c|c|}
\hline $\begin{array}{l}\text { Sensitivity } \\
\text { Parameter }\end{array}$ & $\begin{array}{l}\text { Associated } \\
\text { Phenomenon }\end{array}$ & Distribution & $\begin{array}{c}\text { Range } \\
\left\{\begin{array}{c}\mathbf{\sigma} \sigma \text { or } \min / \\
\text { max }\}\end{array}\right.\end{array}$ \\
\hline Power Table & Decay Heat & Normal & $\pm 7 \%$ \\
\hline $\begin{array}{l}\text { Core Pressure } \\
\text { Losses }\end{array}$ & $\begin{array}{l}\text { RPV internal } \\
\text { circulation }\end{array}$ & Uniform & $\pm 40 \%$ \\
\hline $\begin{array}{l}\text { SG PORV/SRV } \\
\text { valve flow areas }\end{array}$ & $\begin{array}{l}\text { Critical Flow / } \\
\text { Loss of } \\
\text { Secondary Side } \\
\text { Mass }\end{array}$ & Uniform & $\pm 30 \%$ \\
\hline $\begin{array}{l}\text { PRZ PORV/SRV } \\
\text { valve flow areas }\end{array}$ & $\begin{array}{l}\text { Critical Flow / } \\
\text { Loss of Primary } \\
\text { Side Mass }\end{array}$ & Uniform & $\pm 30 \%$ \\
\hline $\begin{array}{c}\text { MCP seal break } \\
\text { area }\end{array}$ & $\begin{array}{l}\text { Critical Flow / } \\
\text { Loss of Primary } \\
\text { Side Mass }\end{array}$ & Uniform & $\pm 20 \%$ \\
\hline SG HX Multiplier & $\begin{array}{c}\text { Primary/ } \\
\text { Secondary Side } \\
\text { Heat Exchange }\end{array}$ & Normal & $\pm 20 \%$ \\
\hline
\end{tabular}

Initial List of Uncertain Parameters

- Automatically calculate the basic statistics and matrices (sensitivity, pearson, covariance, etc.)

- Identify the most relevant parameters for the selected transient 


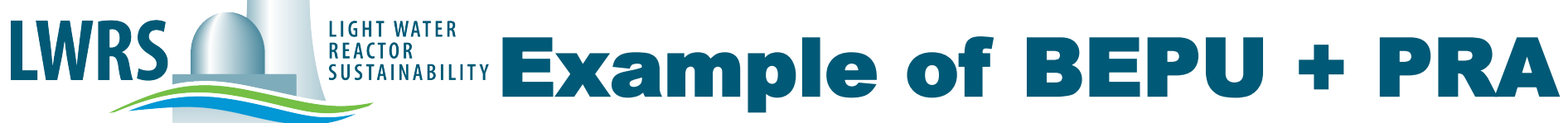

- 4 parameters selected for final perturbation

- MonteCarlo (1000 runs):

- $1122 \mathrm{~K}(95 \%)$

- E(PCT): $903 \mathrm{~K}+/-101$

- ...or Wilks` formula applied with LHS:

- First/fourth order statistics (59 / 153 runs)

- 59 runs $\rightarrow$ "conservative" value for PCT

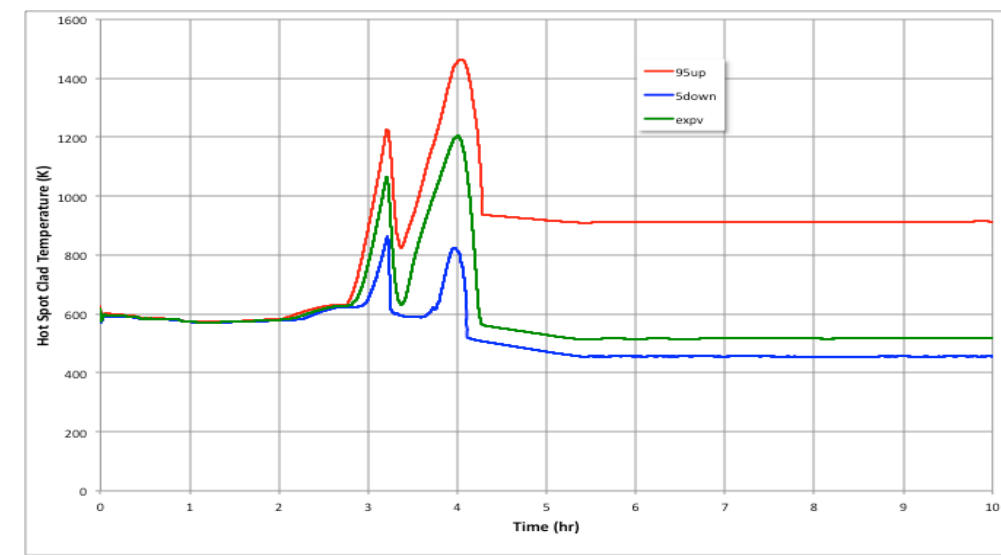

Calculation Results [5/Expected/95 Percentile]

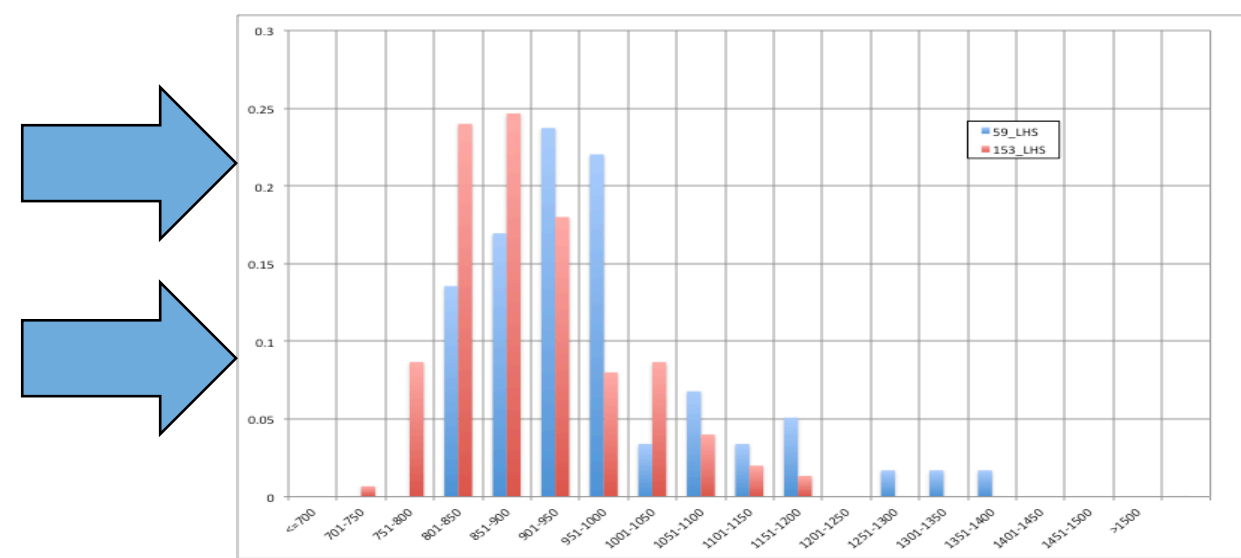

LHS sampling, PCT

[results for Wilks $1^{\text {st }}$ and $4^{\text {th }}$ order statistics] 


\section{LWRS D}

- This was an example for a reference transient.... What if we have multiple transients to be analyzed, like in a PRA Event Tree ?

- E.g., different transients depending by the MCP seal leak rate or different SG depressurization time

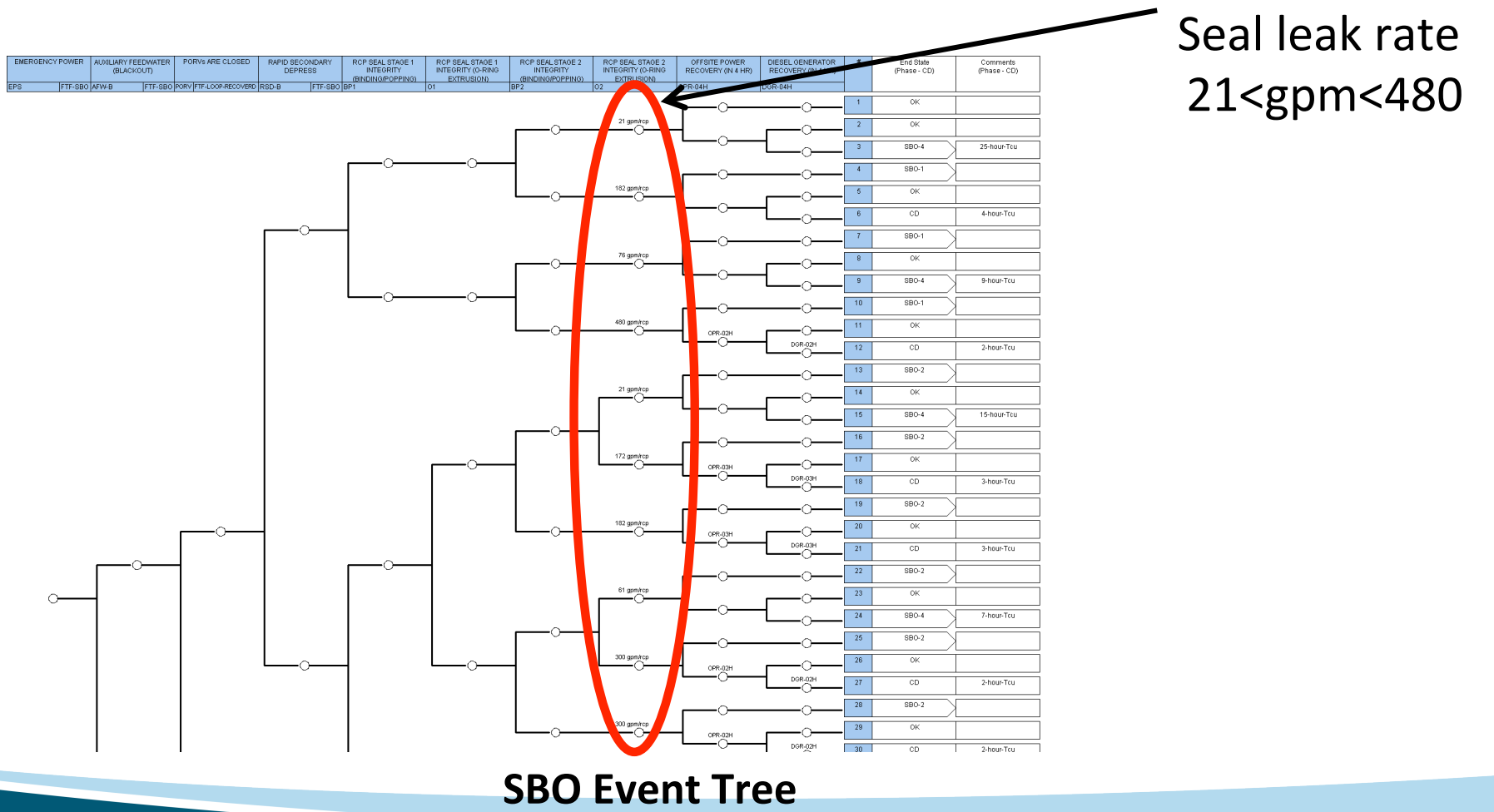




\section{LWRS N}

- Two possible approaches for BEPU+PRA:

1. Assign PDF for each aleatory variable (e.g., operator action times, pump seal leak rate, etc.), then run all scenarios considering also epistemic uncertainties (e.g., core power, RELAP53D uncertainties, etc.) $\rightarrow$ BRUTE FORCE [need Falcon HPC]

2. Explore the NPP status space using Reduced Order Models (=train a mathematical model with RELAP5-3D runs, then use it instead of RELAP5-3D) $\rightarrow$ reduce computational resource needed

- @ INL we are exploring both possibilities

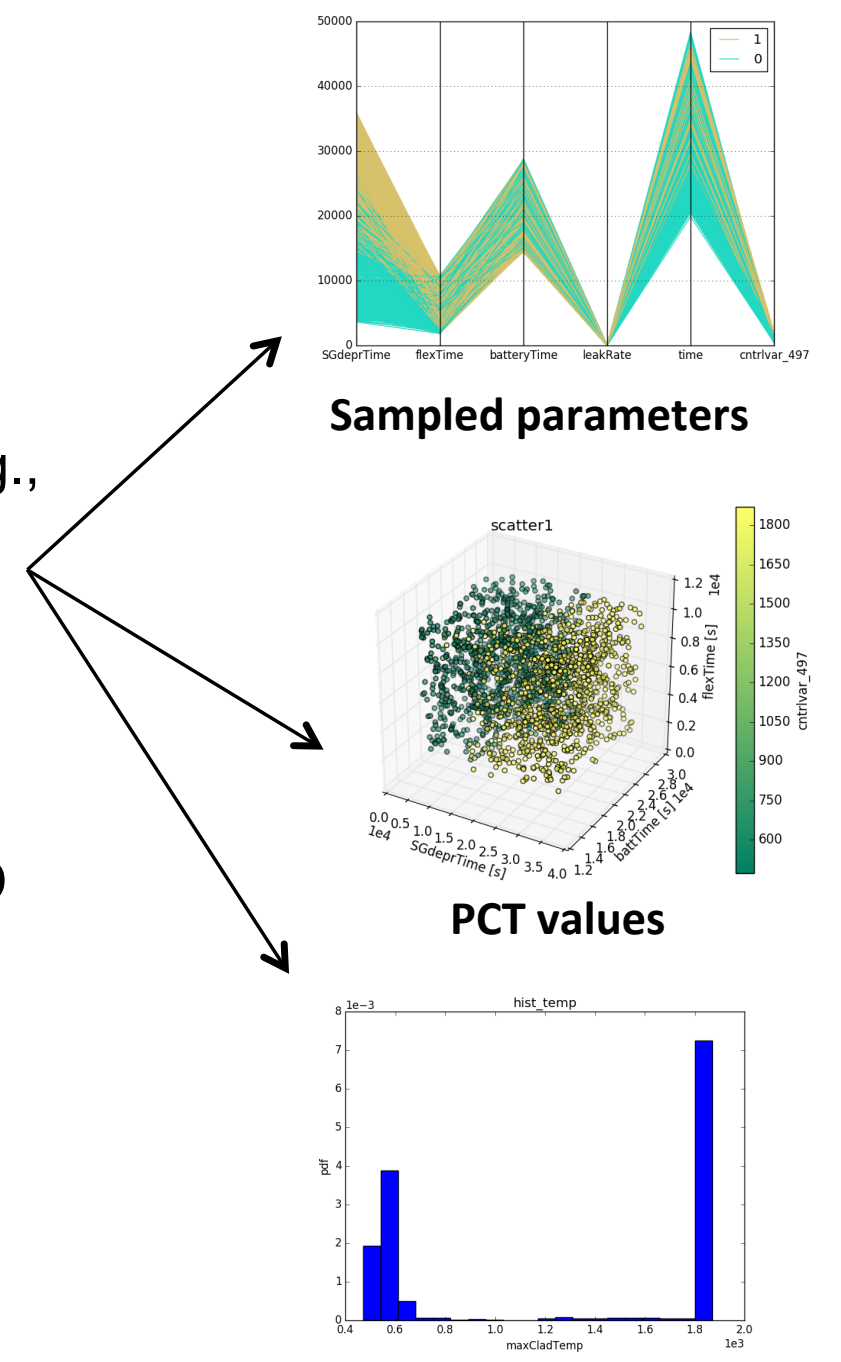




\section{LWRS A}

- Option 2, use of ROM $\rightarrow$ Use of RAVEN Limit Surface Search Algorithm for speeding up calculations of different PRA scenarios

- Limit Surface is an $\mathbf{n}$-dimensional surface describing the plant status as a function of selected plant parameters

- E.g., it can define the boundaries between failed and safe conditions for the nuclear fuel (Core Damage/OK)

- We can approximate a Limit Surface by manually perturbing the code input deck parameters, but...

- numerous computer runs are needed

- manage large databases/lots of inputs/outputs files

- tedious and impractical process $\rightarrow$ can introduce user errors

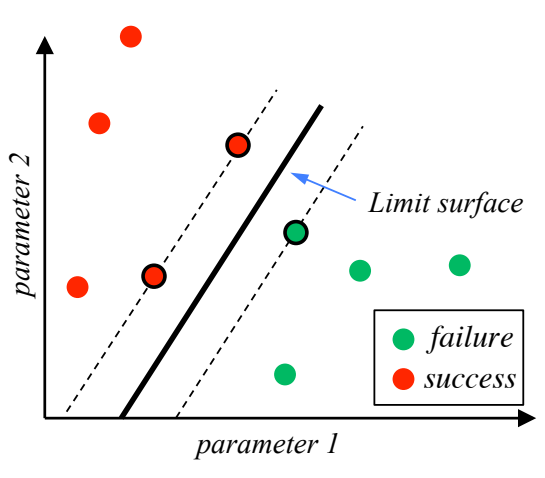

Example of a 2D Limit Surface

\begin{tabular}{|c|c|c|c|c|}
\hline \multirow{2}{*}{ Batteries Failure Time (s) } & \multicolumn{4}{|c|}{ Recovery Time (hr) } \\
\cline { 2 - 5 } & $\mathbf{1 . 5}$ & $\mathbf{2}$ & $\mathbf{3}$ & $\mathbf{3 . 5}$ \\
\hline 0.0 & $\mathrm{~S}$ & $\mathrm{~S}$ & $\mathrm{~F}$ & $\mathrm{~F}$ \\
\hline 1000. & $\mathrm{~S}$ & $\mathrm{~S}$ & $\mathrm{~S}$ & $\mathrm{~F}$ \\
\hline 2500. & $\mathrm{~S}$ & $\mathrm{~S}$ & $\mathrm{~F}$ & $\mathrm{~F}$ \\
\hline 3600. & $\mathrm{~S}$ & $\mathrm{~S}$ & $\mathrm{~S}$ & $\mathrm{~F}$ \\
\hline
\end{tabular}

Manual determination of a LS for a PWR Mitigated Long Term SBO + Battery Failure

- RAVEN provides a solution, thanks to the Automatic Limit Surface Search (LSS) algorithm $\rightarrow$ minimize number of computationally expensive runs and explore the input space 


\section{LWRS N}

- Algorithm for LSS use of Reduced Order Models (ROM)

- Reduce the complexity of the problem

- Set of equations are trained to approximate the original model

- Computationally faster

- Use of ROM for predicting where further input space exploration is more informative

- Use new info for updating ROM (iterative process)

- Several ROM available in RAVEN

- Use of External Library Scikit-Learn

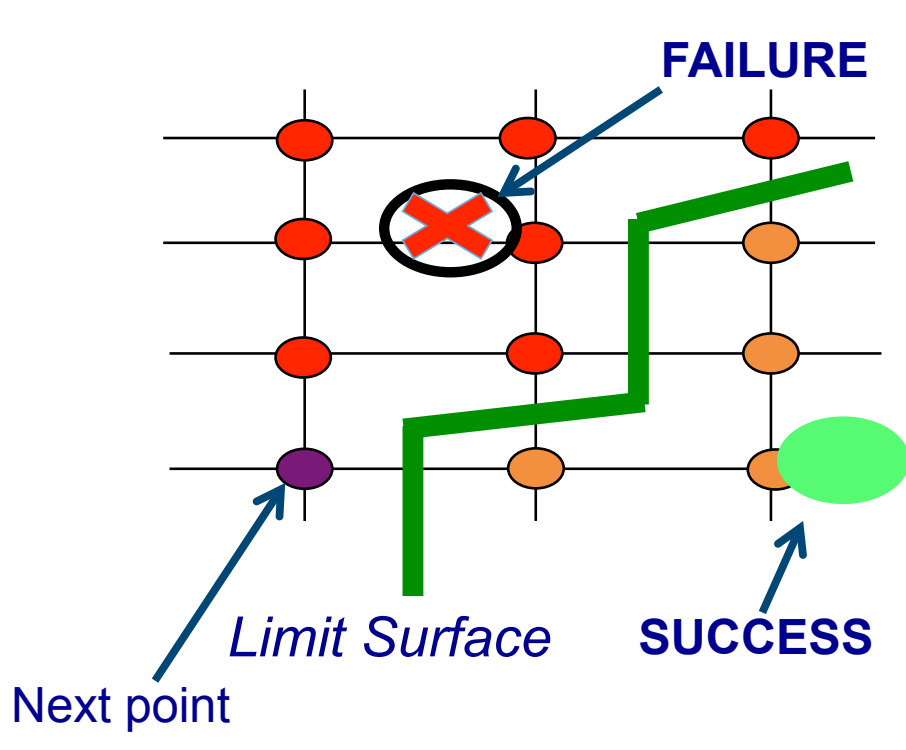

- Open source machine learning library for Python language 


\section{LWRS N}

- Find a LS for a Mitigated Long Term SBO considering Battery Failure Time vs. Recovery Time

- After loosing the AFW, how much time is available to the emergency crew before Core Damage?

- Inform the PRA calculations with LS results $\rightarrow$ runs speed up

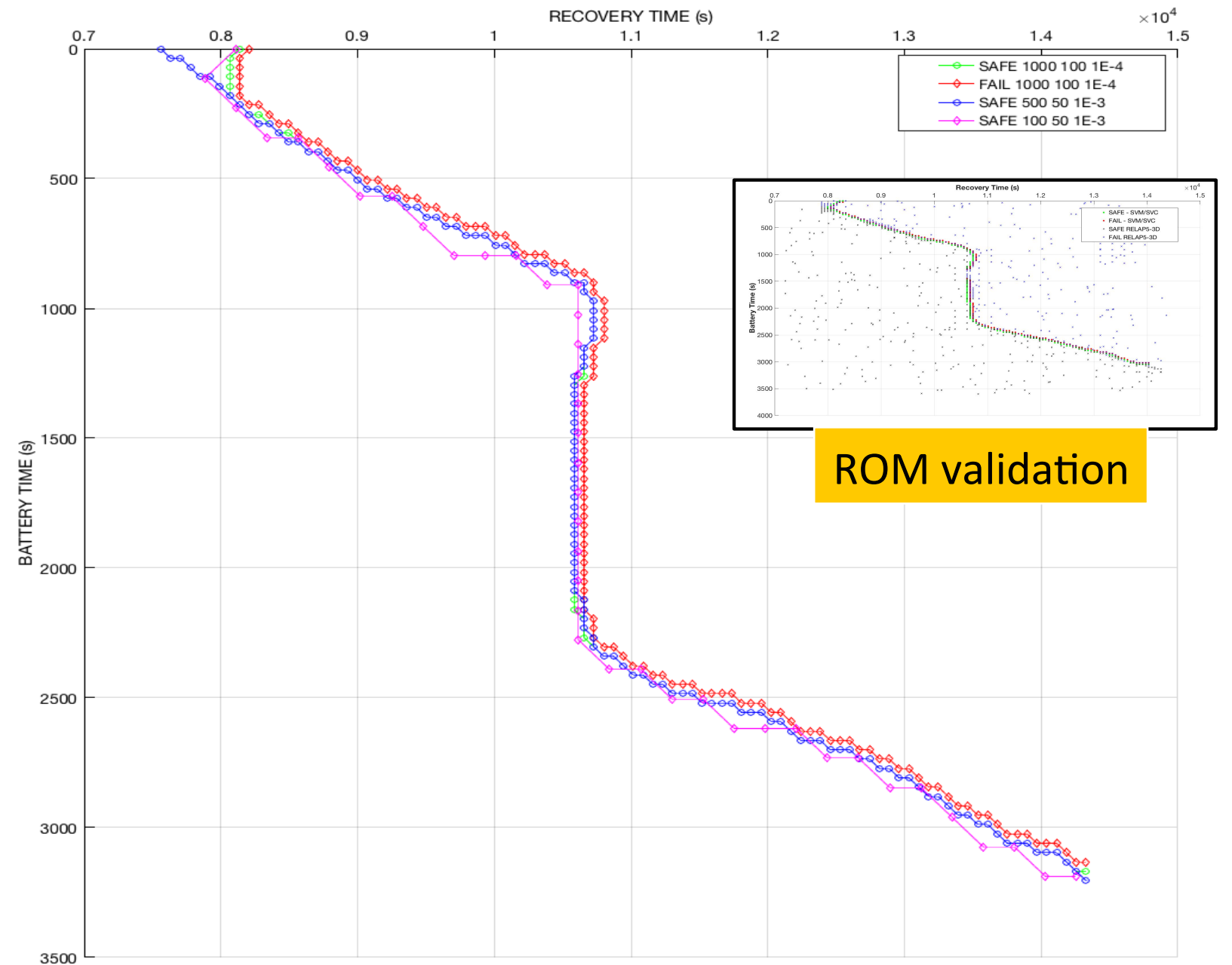




\section{LWRS A}

- Last Step $\rightarrow$ inform the Limit Surface Search with the UQ results

- Performing the LSS including epistemic uncertainty

- 6 dimension LSS (4 epistemic, 2 stochastic)

- $\mathrm{N}$-dimensional surface obtained (6dim)

- Projection of 3 dimensions (Battery Time/Operator action/Core Power)

- Inform the PRA calculations with LS results + UQ $\rightarrow$ runs speed up

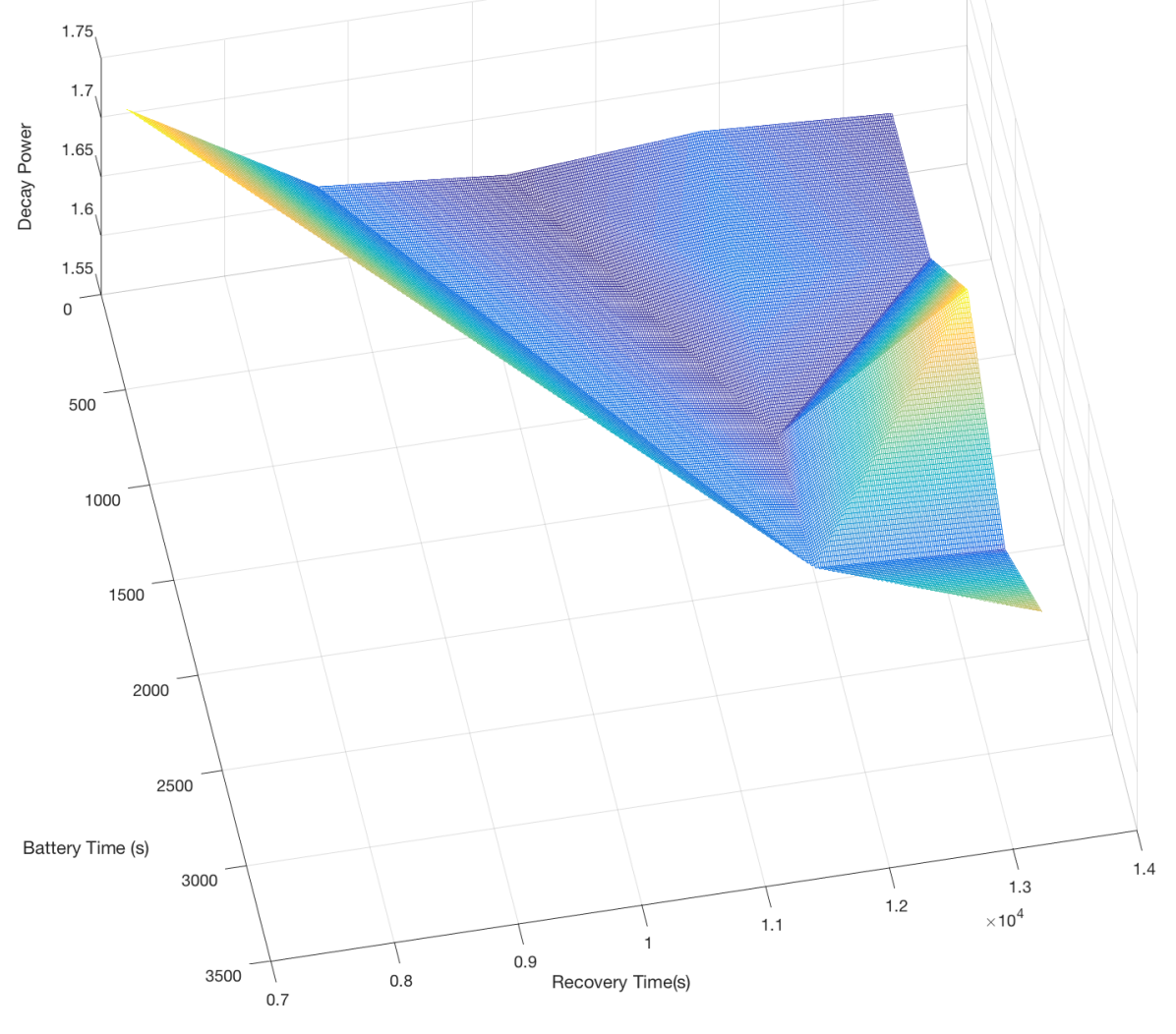

RELAP5-3D/RAVEN Limit Surface including uncertainty parameters 


\section{LWRS N}

- Tools \& methodologies presented so far can help in the evaluation of evolutionary and innovative fuels $\rightarrow$ Accident Tolerant Fuels

- E.g., investigating the ATF capabilities when SBO occur, using LS search technology

- Initial study based on evolutionary ATF fuels (FeCrAl \& Cr-based fuel clad/UO $\mathrm{U}_{2}$ pellet )

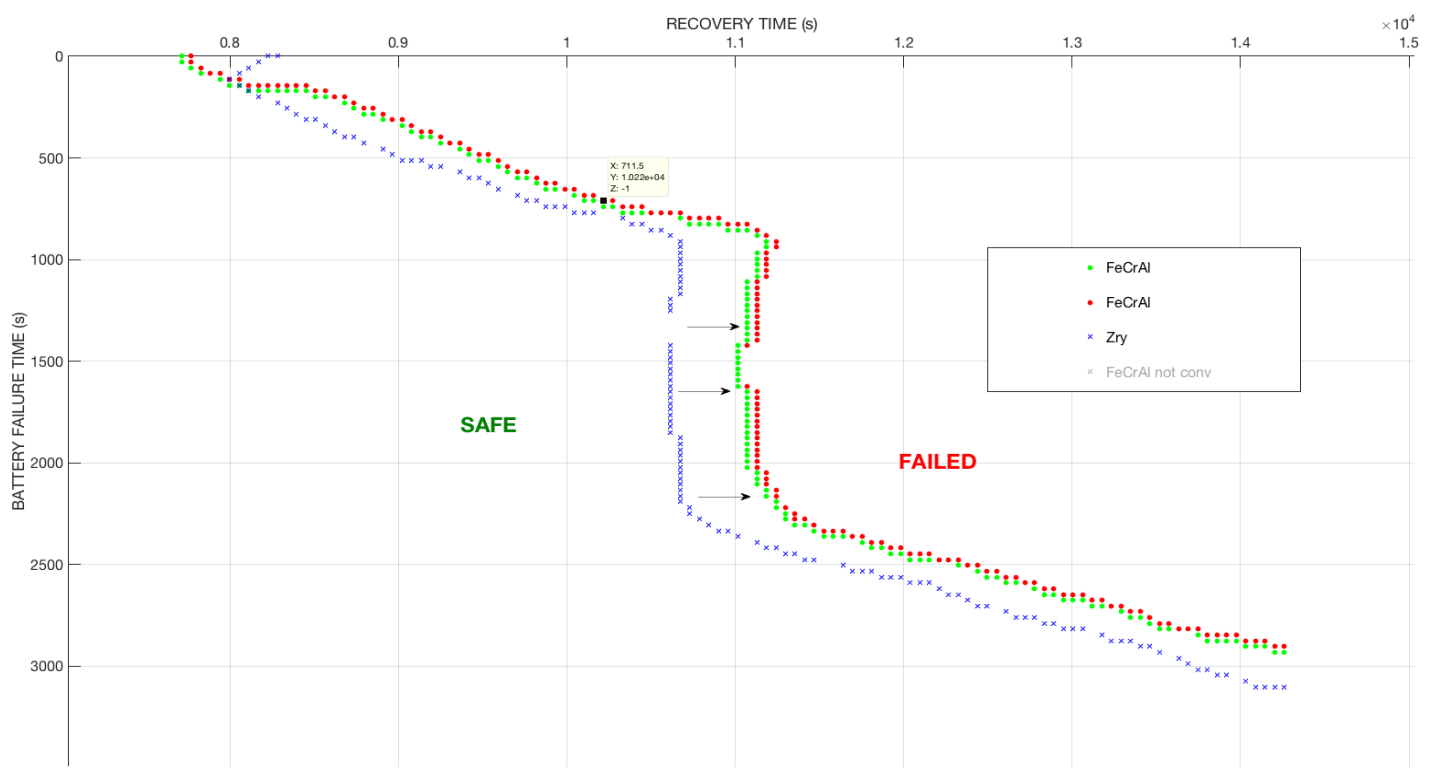

RELAP5-3D/RAVEN Limit Surface for SBO. FeCrAl vs. Zry 


\section{IWRS \\ 10CFR50.69 Evaluation}

- INL working on tools and methods for advanced application of 10CFR50.69 rule

- Scope: identify SSC that can be moved in different category (safety/non safety significant vs safety-related/non safety related)

- LWRS/RISMC tools

- RELAP5-3D/RAVEN

- FY2017:

- defined different PRA metrics (Risk-Importance Metrics) in RAVEN

- tested on LB-LOCA problem (2A)

- Activity continuing in FY2018, applying the methodology to a LBLOCA spectrum(8"-2A) 


\section{LWRS A}

- CD probability:

- Dynamic PRA (RAVEN-RELAP5): 8.24 E-3

- Classical PRA (SAPHIRE): 8.13 E-3

- Event sequence probabilities:

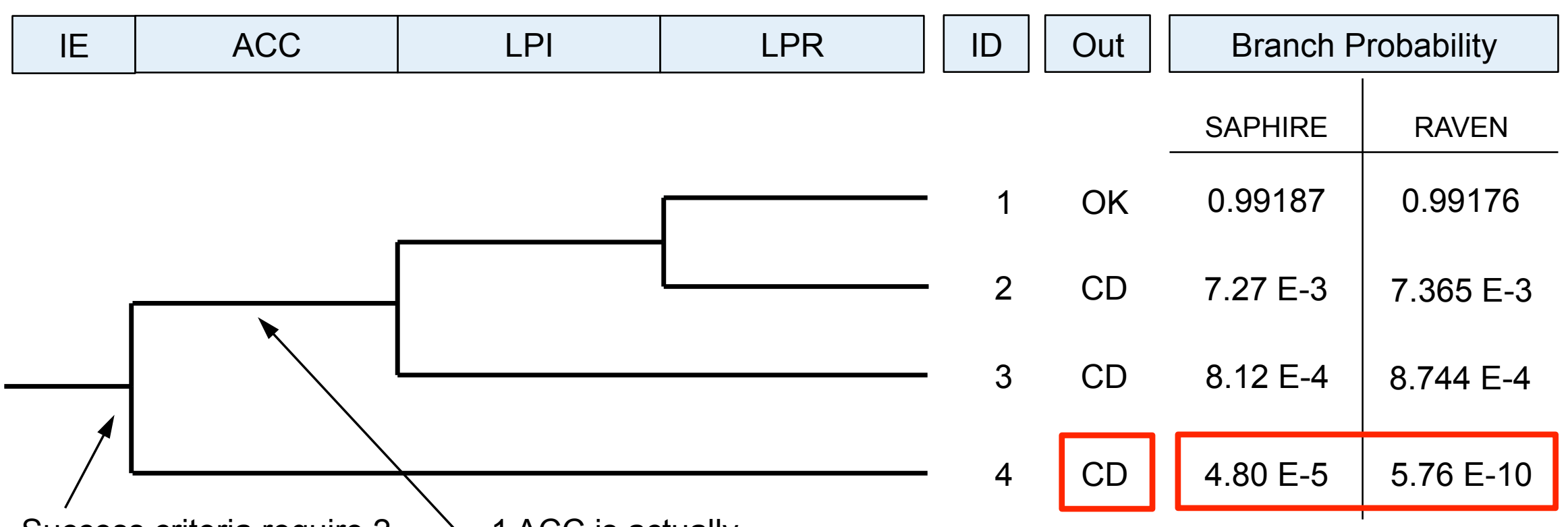

Success criteria require 2 out of 2 ACCs to function
$1 \mathrm{ACC}$ is actually sufficient, but ... 


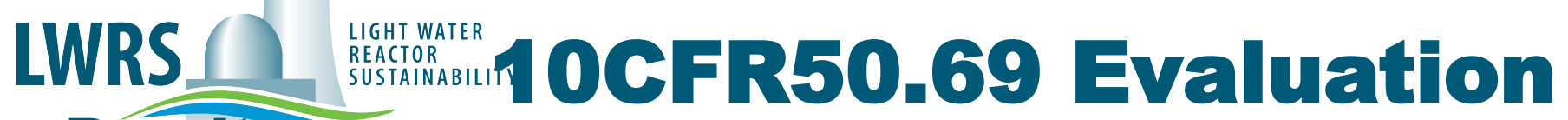

\section{Results}

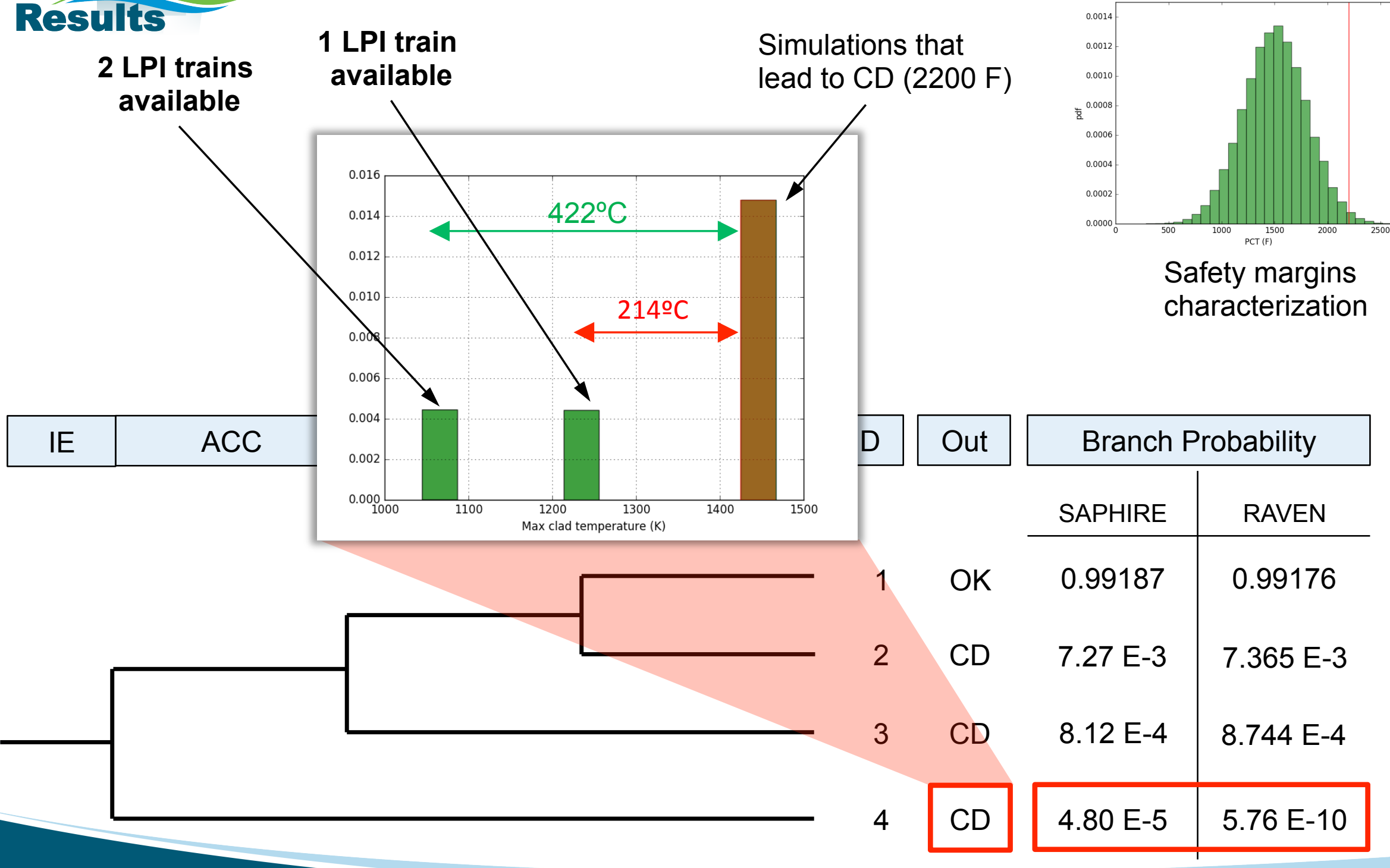




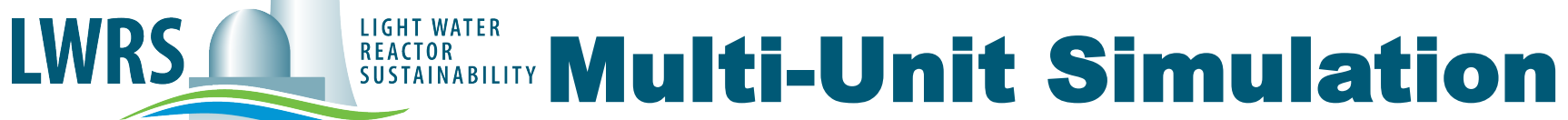

- INL developing tools and methods for Multi-unit dynamic PRA simulation

- Scope: perform an integral multi-unit plant analysis

- Application: seismic induced SBO

- Tools: RELAP5-3D/RAVEN

- Relevant results:

- RELAP5-3D TH modeling of 3 PWRs + 3 SFP

- Human reliability models

- Modeling of control logic at the site level

- Use of ROMs

- Data analysis of large and complex dataset 


\section{LWRS A Multi-Unit Simulation}

- Simulation of different emergency procedures for a SBO

- PWR1 at full power (100\%)

- PWR2 in mid-loop condition

- PWR3 recently out of refueling and now at full power $(108 \%)$

- FLEX equipment for emergency water injection + swing diesel generators

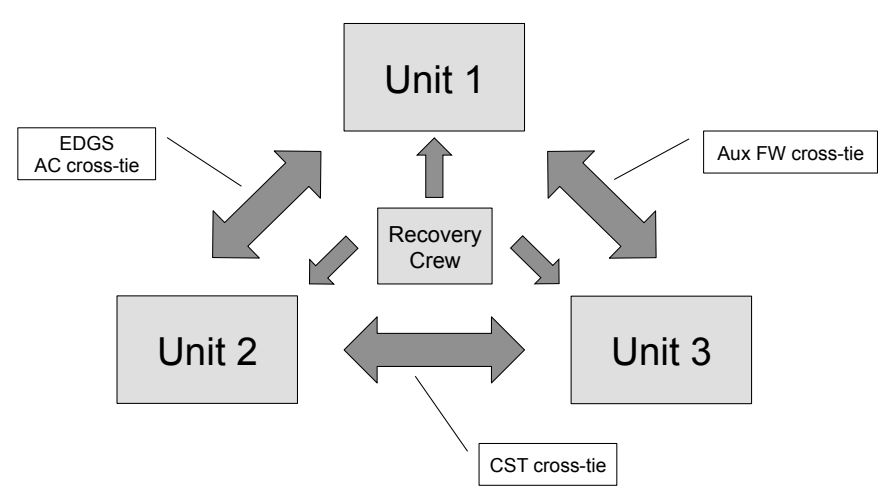

- RELAP5-3D used for training RAVEN ROMs $\rightarrow$ used for the final simulation $\rightarrow 1.1$ Millions samples

- Determined relevant Plant Damage States (PDS) and their probabilities

CST is intact + multiple recovery actions available

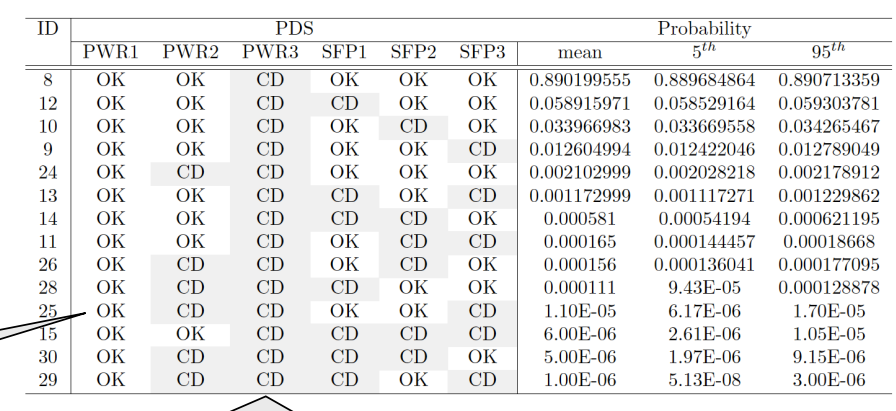

PWR3 can be recovered only within 50 min after SBO condition 


\section{LWRS Conclusions}

- INL is developing tools \& methods for Risk-Informed Safety Margins

Characterization under the US DOE LWRS program

。 increase LWRs economic reliability

- Different activities ongoing, including

- BEPU + PRA safety analysis method development, ATF, 10CFR50.69, Multi-unit simulation

- Possible collaboration with STP on one/different R\&D topics 


\section{$\sqrt{A \sqrt[M]{M}}$}

NUCLEAR ENCINEERING TEXAS A\&M UNIVERSITY Risk-Informed Safety Margin Characterization
(RISMC) Industry Application Demonstration -
ECCS/LOCA Cladding Acceptance Criteria

Kaleb Neptune

Status Update February $14^{\text {th }} 2018$
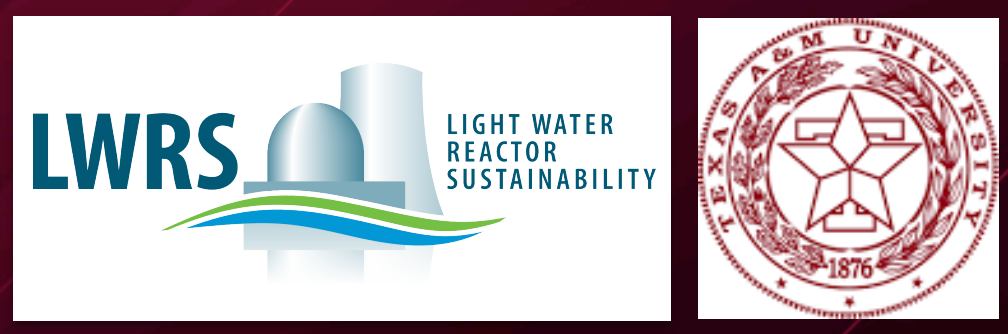


\section{Table of Contents}

Purpose

Methods

Sources

Validation

Tables

Nodalization

Applications

Path Forward 


\section{Purpose}

Texas A\&M University is assisting INL on the development and application of LOTUS for STP by constructing an associated thermal-hydraulics model of a generic PWR, with STP features. 
Identified data as:

1. Non-Proprietary - publicly available $>$ Generate a table relating parameters to sources

2. Proprietary - not publicly available $>$ Fill table with modified parameters. 
Hydrodynamic Components - Geometry

Flow Area

Hydraulic Diameter

Flow Length

Elevation Change

Heat Structures

Surface Area

Thickness

Materials

Heated Diameter

Other 


\section{Sources Identification}

\section{References}

\section{NRC Website}

Pressurized Water Reactor (PWR) Systems.

Retrieved from :

http://www.nrc.gov/reading-rm/basic-ref/students/foreducators/04.pdf

Westinghouse Technology Systems Manual.

Retrieved from :

http://www.nrc.gov/docs/ML1122/ML11223A213.pdf

Bulletin 96-01: Control Rod Insertion Problems.

Retrieved from :

http://www.nrc.gov/reading-rm/doc-collections/gen-comm/bulletins.html

NRC Delta 94 STP steam generators.

Retrieved from :

http://pbadupws.nrc.gov/docs/ML1006/ML100670440.pdf

\section{US Universities}

MIT Nuclear Science and Engineering. PWR Description (Presentation).

Retrieved from

https://ocw.mit.edu/courses/nuclear-engineering

Virginia Lab EDU, The Westinghouse Pressurized Water Reactor Nuclear Plant

Retrieved from

http://www.virlab.virginia.edu/Energy_class/Lecture_notes 


\section{Sources Identification}

\section{References}

\section{International Sources}

IAEA, Assessment and management of ageing of major nuclear power plant components important to safety Primary piping in PWRs

Retrieved from :

http://www-pub.iaea.org/MTCD/publications/PDF/te_1361_web.pdf

IAEA, Assessment and management of ageing of major nuclear power plant components important to safety Steam Generators

Retrieved from :

http://www-pub.iaea.org/MTCD/publications/PDF

\section{Formulas}

Energy KTH, Applied Reactor Technology and Nuclear Safety

Retrieved from :

http://www.energy.kth.se/courses/4A1627/Material2005 


\section{Example Data Table (Leg)}

\begin{tabular}{|l|l|l|l|l|}
\hline $\begin{array}{l}\text { Component } \\
\text { JX05 }\end{array}$ & $\begin{array}{l}\text { Parameter } \\
\text { flArea [ft2] }\end{array}$ & $\begin{array}{l}\text { Value } \\
\text { hyD [ft] }\end{array}$ & $\begin{array}{l}\text { Reference } \\
\text { Nomponent }\end{array}$ & $\begin{array}{l}\text { Notes } \\
\text { Matches X04-2 (and rest of HL) }\end{array}$ \\
\hline Parameter & Value & Reference & Notes \\
\hline X04-2 & flArea [ft2] & 4.5869 & & A=PI*hyD^2/4 \\
\hline & hyD [ft] & 2.4167 & {$[3]$} & Westinghouse PWR Manual (PDF pg 19/245) \\
\hline & flLen [ft] & 4.4 & & changed to (new HL total Length)/5 \\
\hline & vol [ft3] & 20.182 & & vol=flArea*flLen \\
\hline & elCh [ft] & 0.0767 & & elCh=flLen*sin(vAng) \\
\hline vAng & 1 & & \\
\hline
\end{tabular}




\section{Validation}

$\checkmark$ Steady State Simulations

$\checkmark$ Steady State results were compared to reference PWR SS simulations

$\checkmark$ LOCA scenarios simulated and compared with reference CLB LOCA results 


\section{A]}

Plant Nodalization

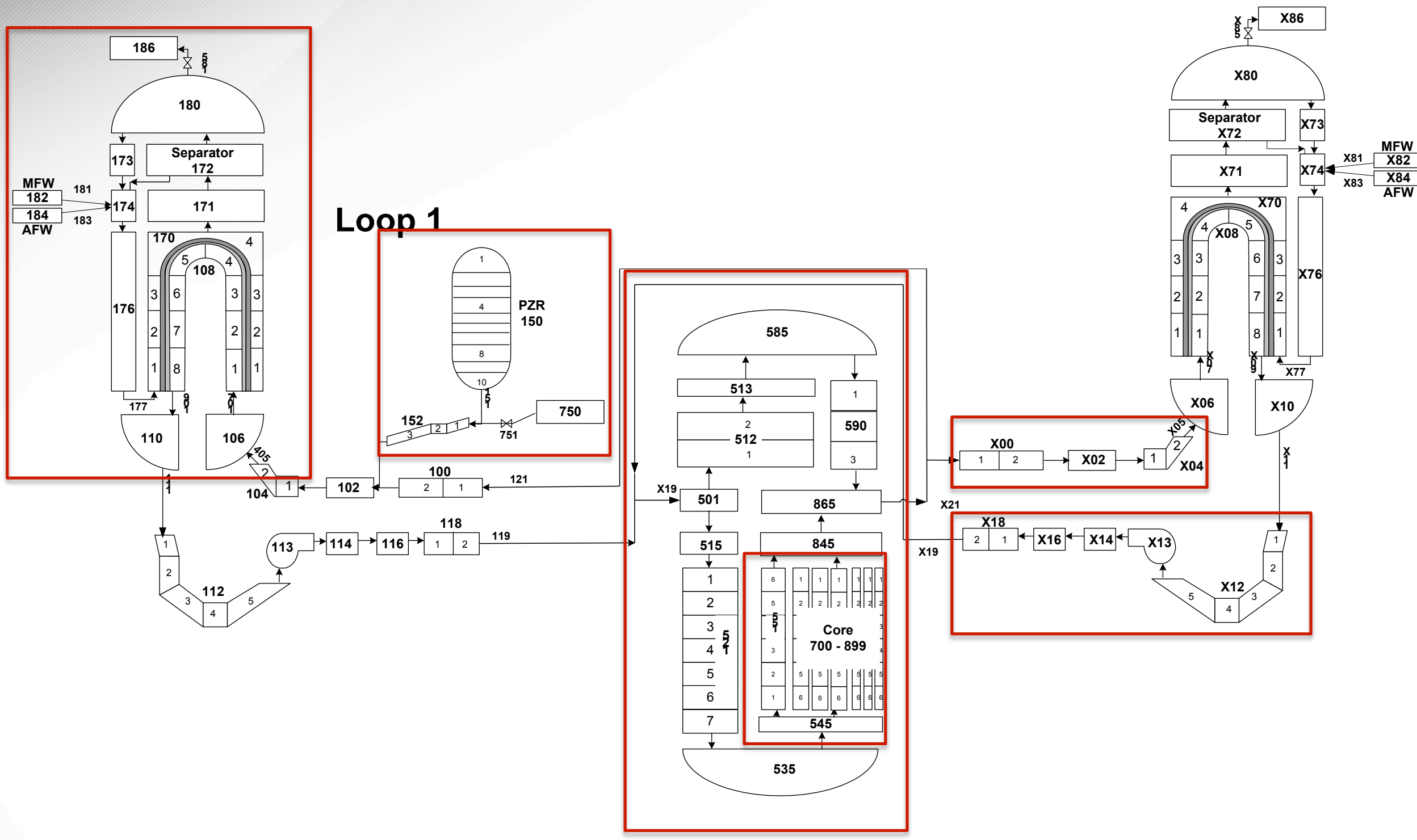




\section{Core Nodalization}

Typical Core Model

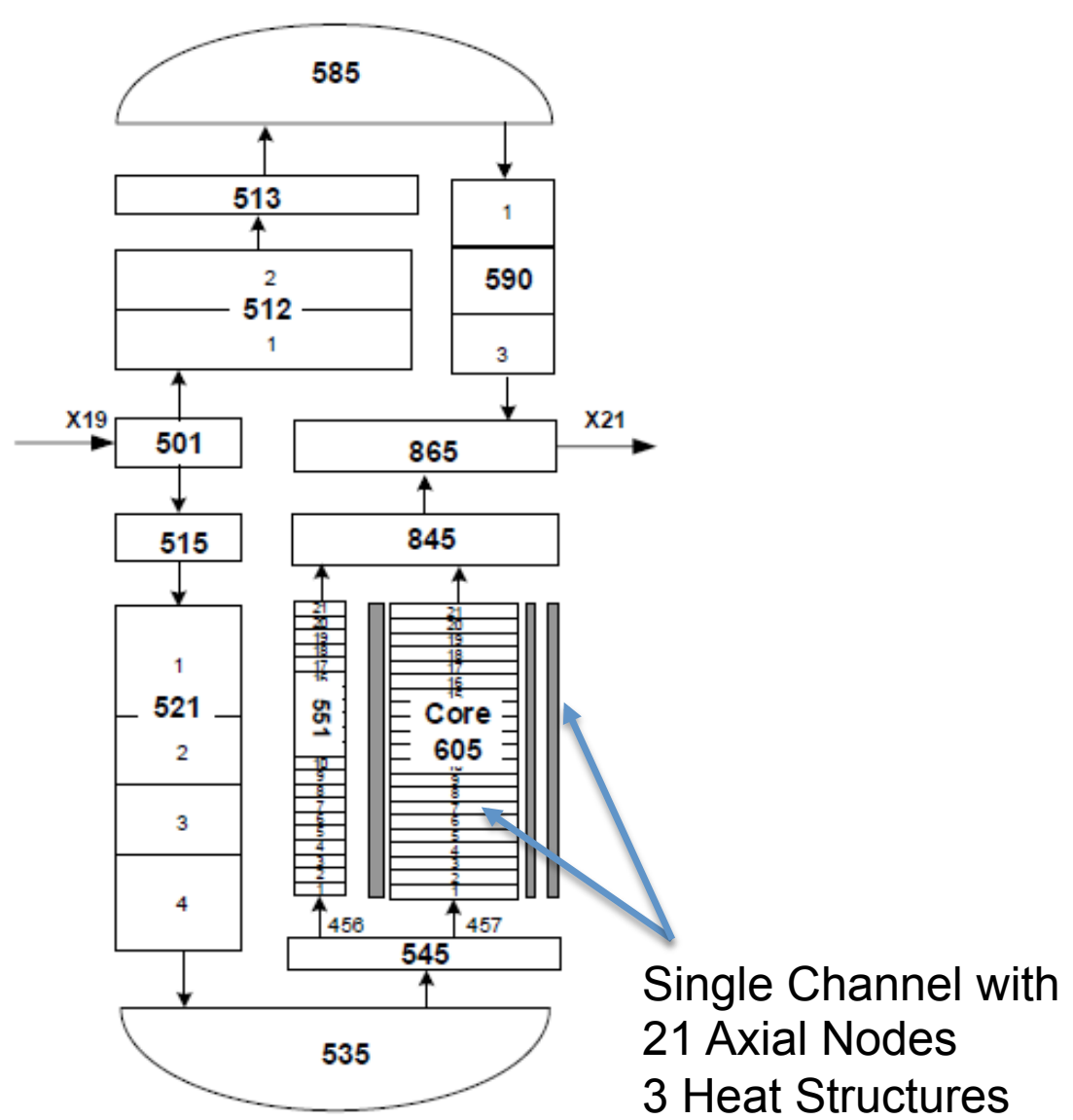

Modified Core Model

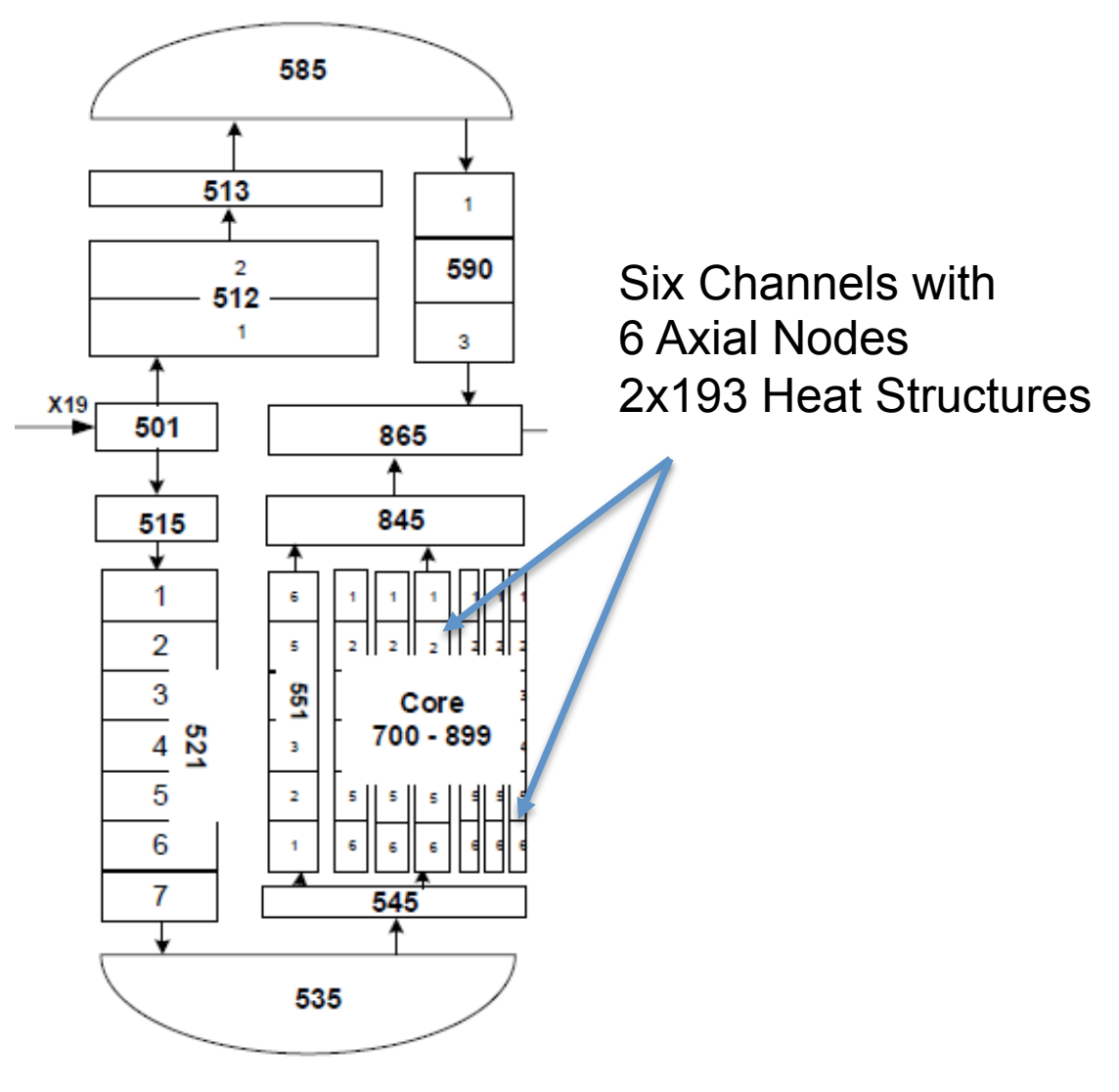




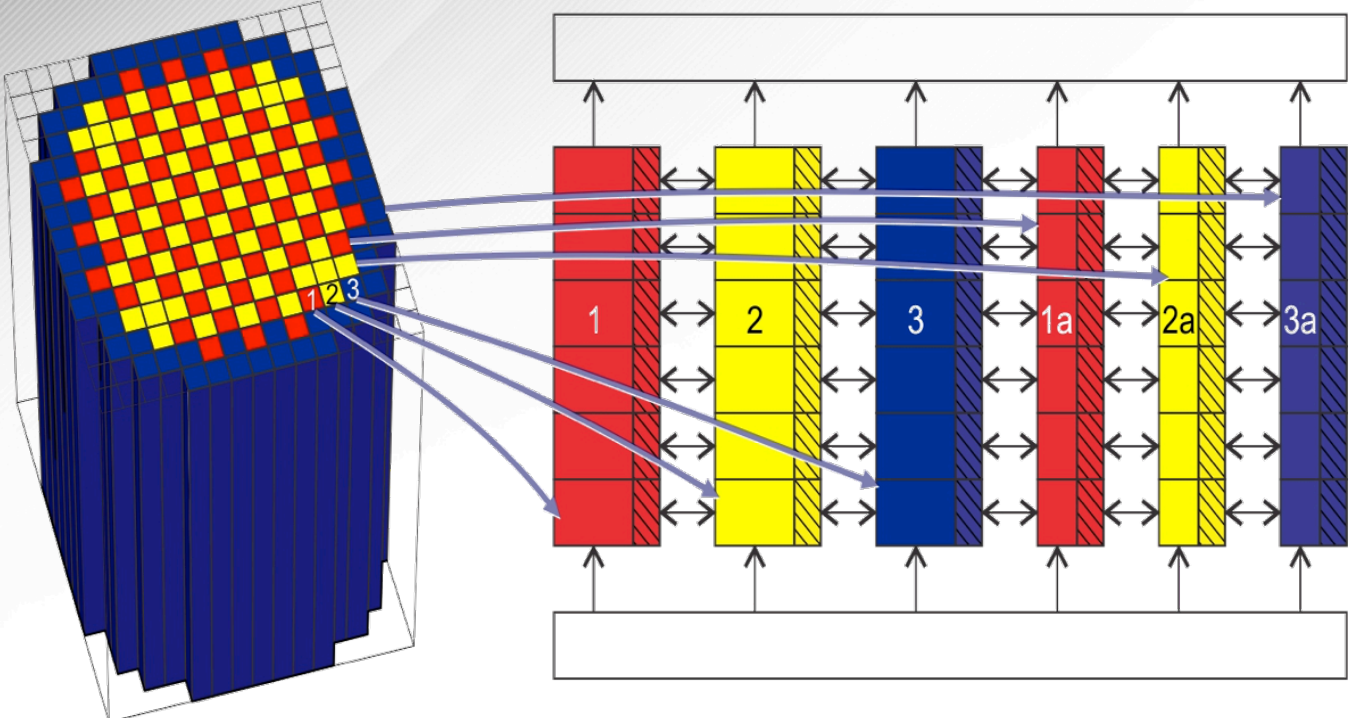

Thermal Fluid Dynamic Model

- Fuel assemblies are grouped by

- Fresh Fuel (red)

- Once Burned Fuel (yellow)

- Twice Burned Fuel (blue)

- Six total flow channels exist

- One Average Channel per fuel group

- One Hot Channel per fuel group

- Connected laterally to allow cross-flow. 


\section{Modified Core Model}

Two Sets of Heat Structure per Assembly

- Highest Power Rod (Hot Rod)

- Average of Rods Remaining in Assembly

- Total of 193 Average Assemblies and $193 \mathrm{Hot}$ Rods

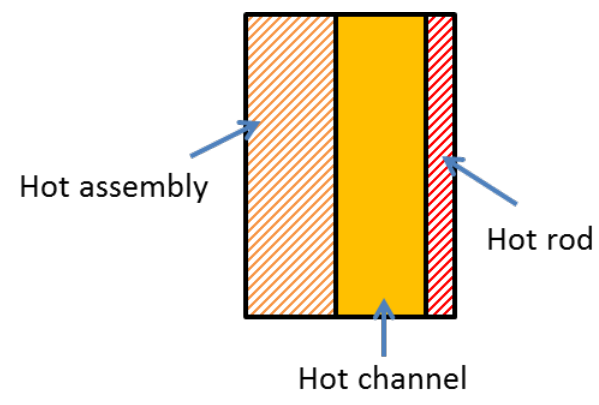

Data used to develop the model:

- Publicly Available STP FSAR

- Other Public source

- Assumed parameters

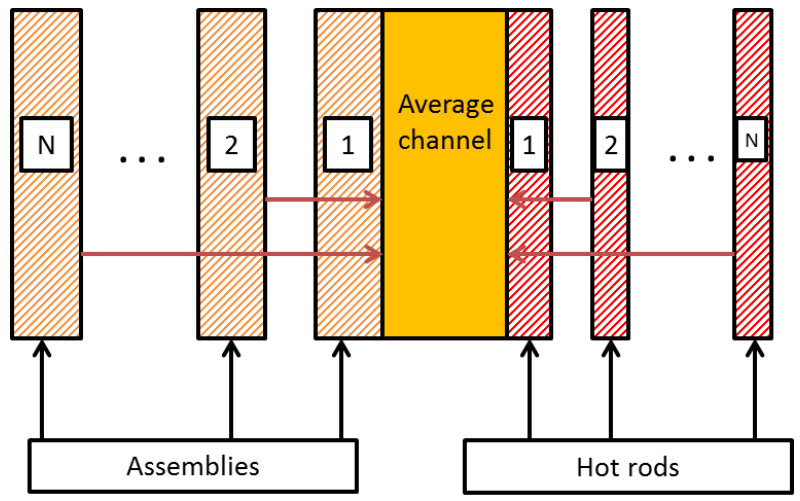




\section{Applications}

The Thermal-Hydraulic model provided by TAMU has been used for:

Development of LOTUS as an interface between:

- PHISICS

-HELIOS-2

Coupling techniques between RELAP5-3D:

- RAVEN

- FRAPCON 


\section{Path Forward}

- Include Plant Features for SBO

Simulations

- Secondary SG relief valves

- Pressurizer detailed parameters

- New Simulations 


\section{$\operatorname{Ar|r} \mid$}

\section{Questions?}




\section{STP/TAMU/INL Collaboration Meeting RISMC Applications}

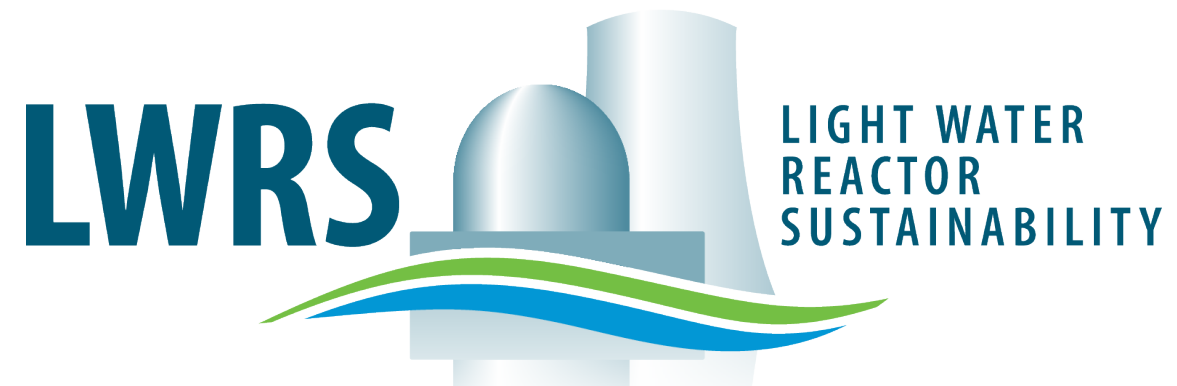

Hongbin Zhang

Idaho National Laboratory

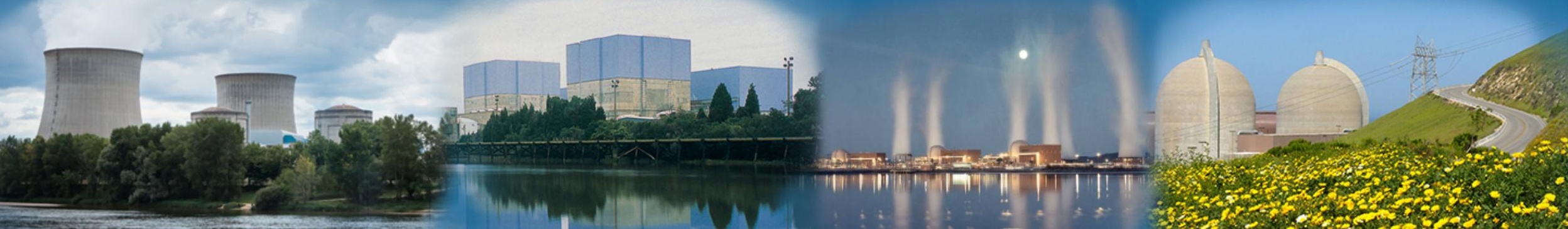




\section{LWRS D}

- Present a preliminary RISMC model to South Texas Project, including plant model interfaces for best estimate plus uncertainty loss-of-coolant accident analysis using existing codes. Analysis results will be presented from applying the coupled core design, fuel/clad and systems analysis framework LOTUS with the existing baseline codes (LOTUS-B) to large break loss-of-coolant accident.

- To discuss a pathway forward to expand applications of RISMC toolkit to STP on risk-informed applications and the emerging issues such as Accident Tolerant Fuel, FLEX, Resilient NPP designs, Risk-Informed Decision Making Applications, etc. 


\section{Part I}

\section{LOTUS-B Application on a Generic PWR Model Based on STP}




\section{LWRS (nackground}

- The existing NPP fleet is facing economic challenges due to:

- Low natural gas price

- Rapid deployment of renewable energy sources

- Additionally, the existing NPP fleet is facing regulatory challenges, e.g.

- 10 CFR $50.46 \mathrm{c}$

- Reducing fuel cost is one area that contributes to the improved economic viability and enhanced safety of the existing fleet

- Accident tolerant fuel

- Higher burnup of the fuel

- Optimized fuel and loading pattern design

- Load following and flexible operating strategies

Multi-physics, multi-scale analysis of core/fuel/systems in the context of bestestimate plus uncertainty (BEPU) methodology is desired. 


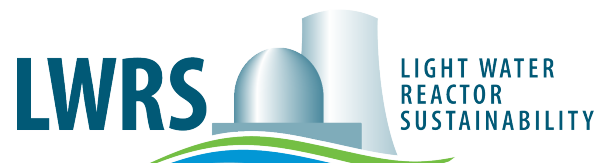

\section{RISMC Application for LOCA Analysis $\rightarrow$ LOTUS (LOCA Toolkit U.S.)}

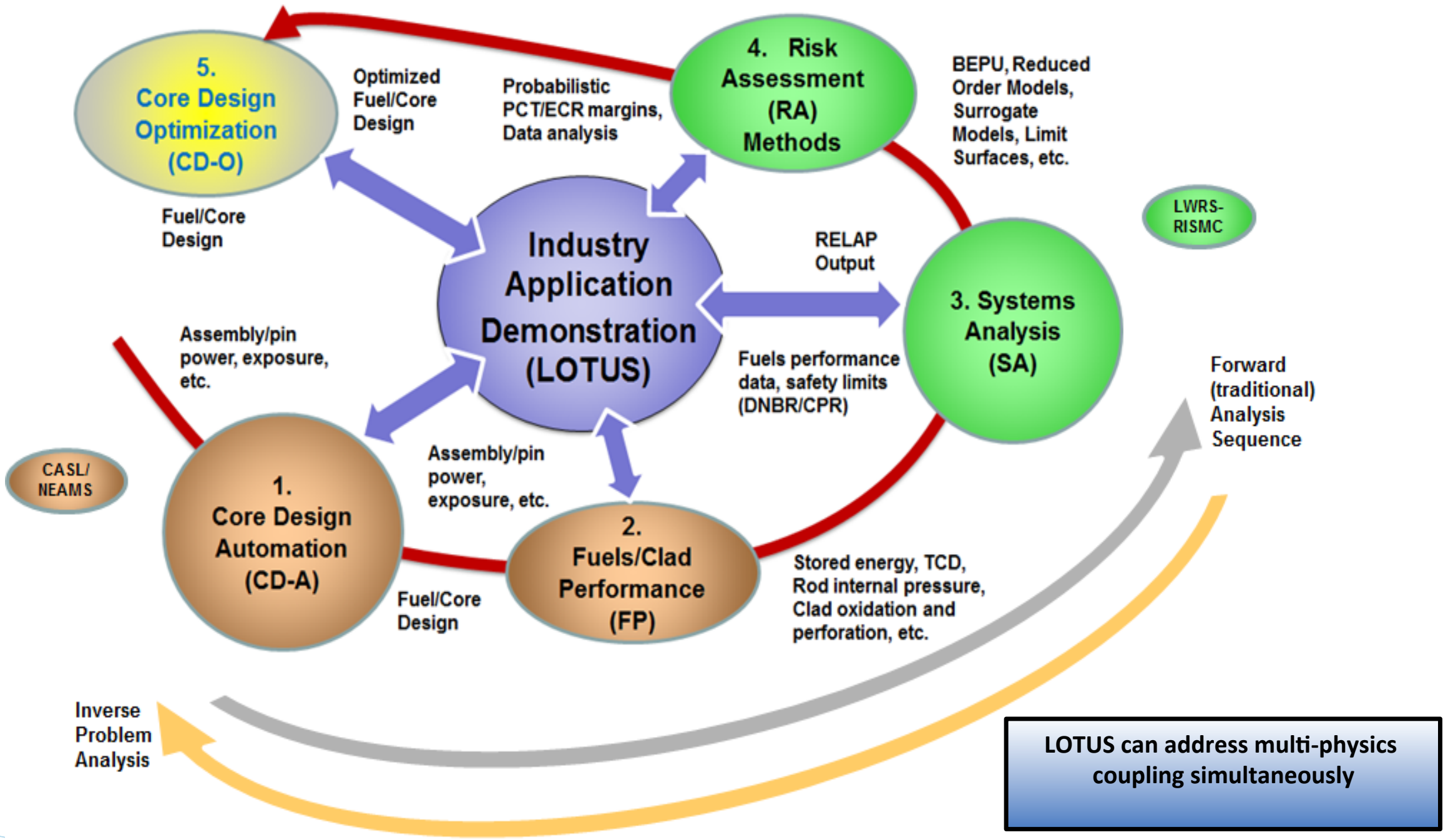




\section{IWRS \\ Data Stream of the LOTUS-B \\ r (Baseline Tools) Framework}

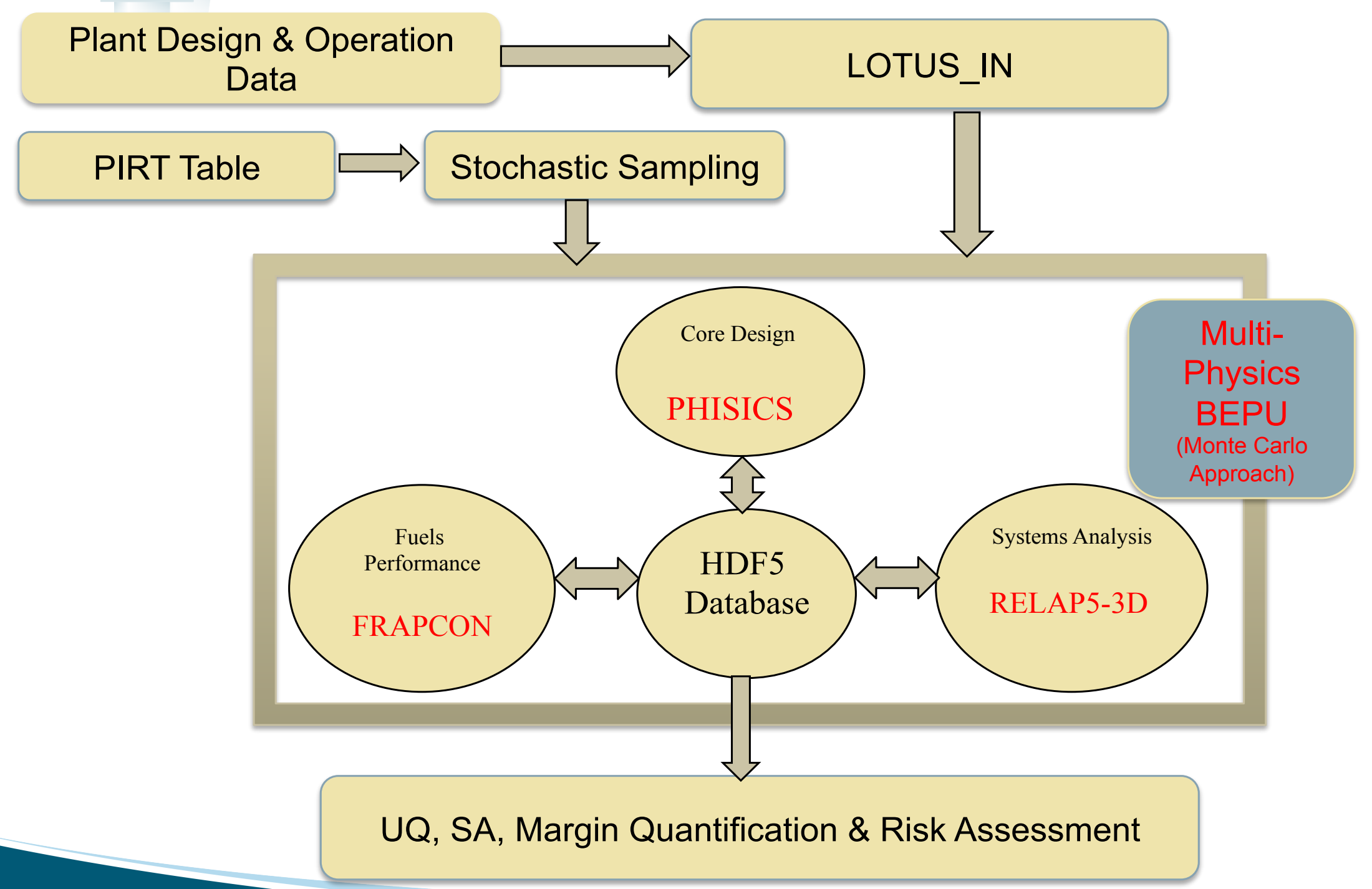


- INL collaborated with Texas A\&M University and STP on the LWRS LOTUS development.

- A generic four-loop PWR plant model has been built for the RELAP5-3D code based on STP NPP.

- All the proprietary information has been replaced with generic and/or publically available information such as STP UFSAR, Rev. 18 from the NRC Website.

- The LOTUS-B toolkit (PHISICS, FRAPCON and RELAP5-3D) has been applied to the generic PWR model to perform best estimate plus uncertainty analyses for LB-LOCA accident to demonstrate compliance to the proposed new rulemaking in $10 \mathrm{CFR}$ 50.46c. 


\section{IWRS \\ PWR Core Design - Generic Design Based on STP}

\section{- Coupled RELAP5/PHISICS}

- $1 \mathrm{TH}$ channel per assembly

- Boundary conditions at

lower and upper plena

- Developed PWR core similar to STP core

- 3.8 GWth

- 14 feet Westinghouse core

\section{- Design Criteria}

- 18 month cycle

- High energy/low leakage

- Equilibrium assumed after 8 cycles

- Enrichment 4.2\%-4.6\%

- Fresh/1/2/burned map from a similar PWR

IFBA distribution obtained by optimization process

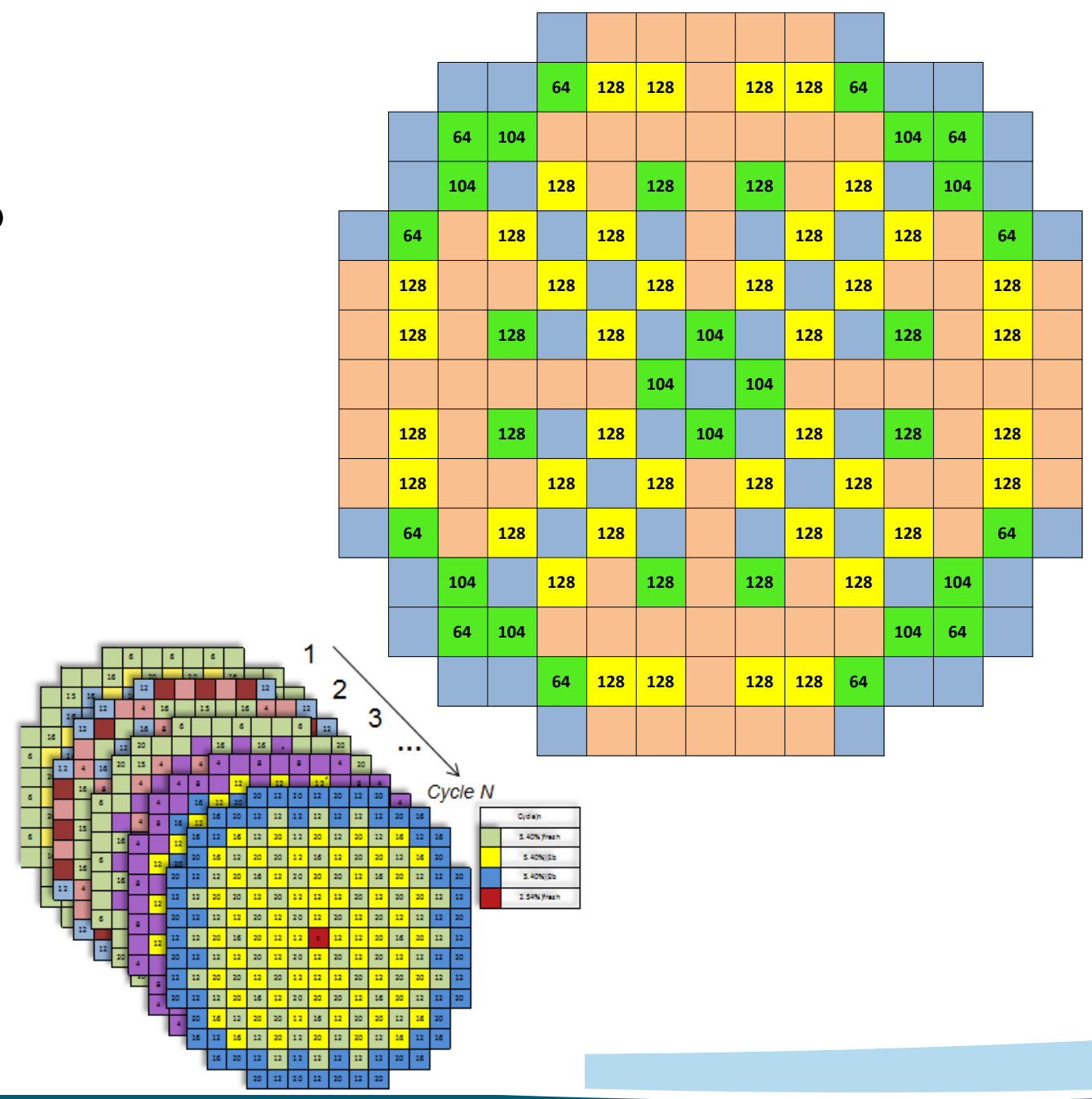




\section{LWRS \&}

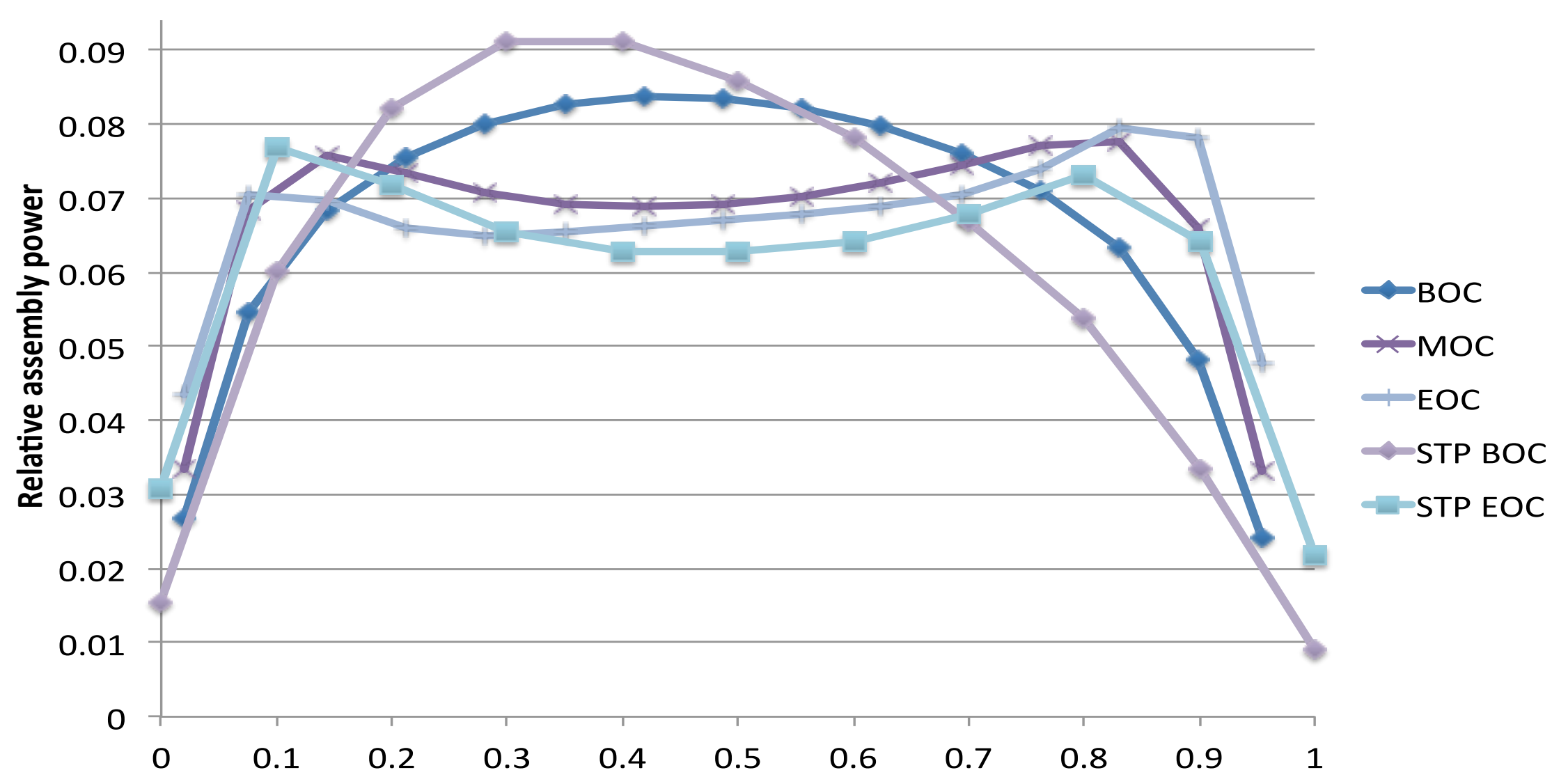




\section{Transient power maneuvers for STP

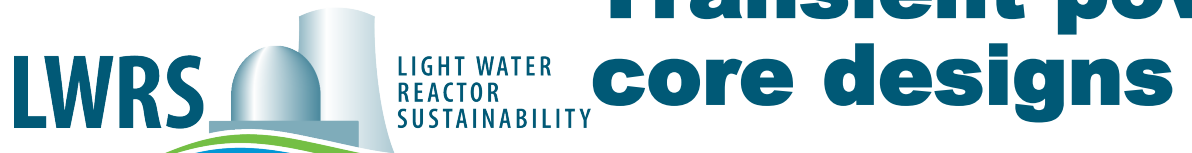
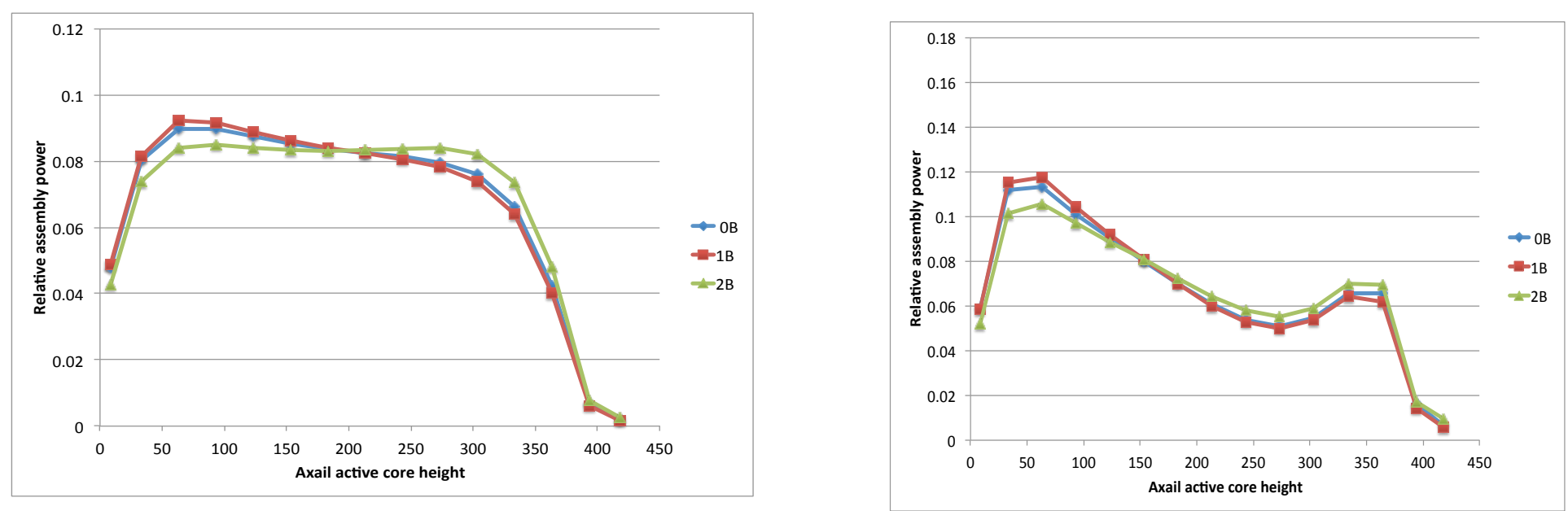

$\mathrm{BOC}$

300 Days

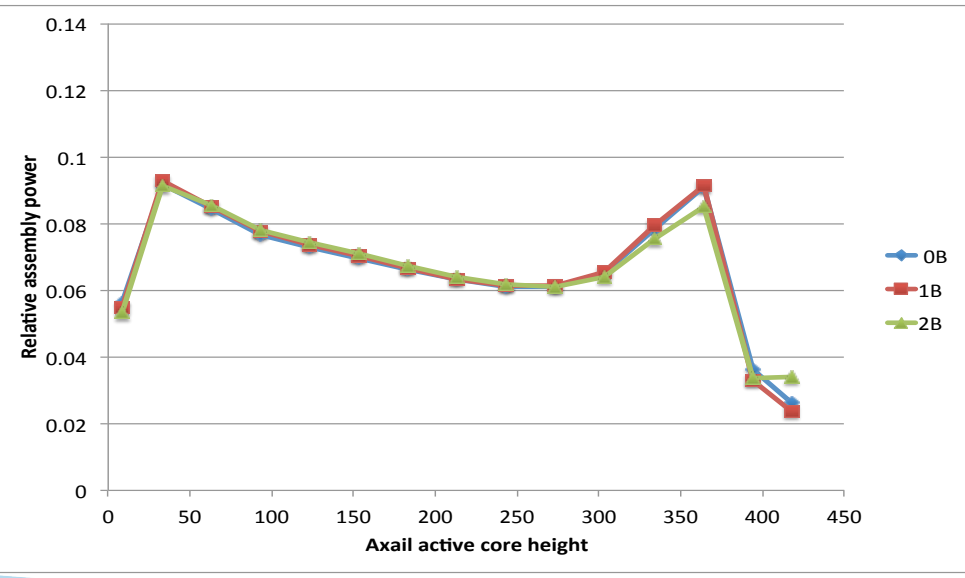

EOC 


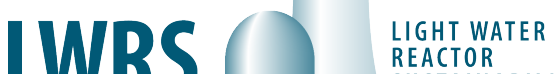 \\ Fuels/Clad Performance (Baseline)}

- Fuel mechanics

- RELAP5-3D includes rupture model and ballooning model

- But we need detailed analysis of fuel rods' behaviors such as the fission gas released, rod internal pressure, and fuel-cladding mechanical interaction, cladding $\mathrm{H}$ content etc., FRAPCON

- The power history data is automatically retrieved by LOTUS from the core design results going into a FRAPCON input

Power history for the hot rod (one assembly)

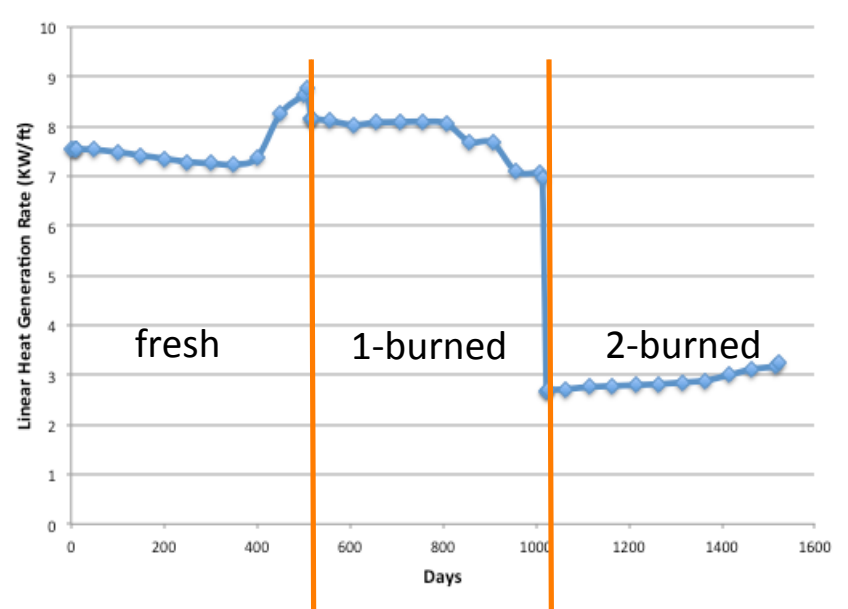

Cladding hydrogen content vs. rod average burn-up (all assemblies)

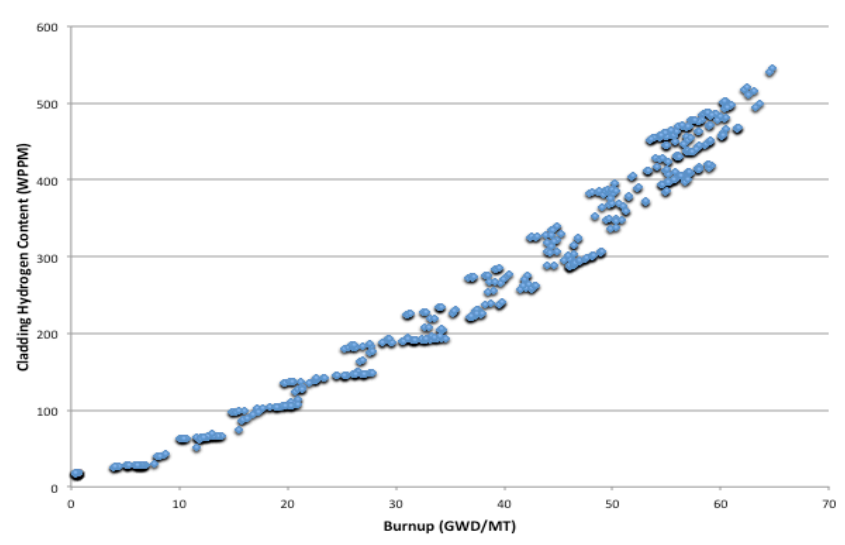


- A RELAP5 model is built for a generic PWR based on the STP NPP:

- Reactor Vessel

- Downcomer

- Bypass

- Lower/Upper plena

- Core

- Upper head

- Reactor coolant system

- 4 primary loops

- ECCS

- Low pressure injection (LPI)

- High pressure injection (HPI)

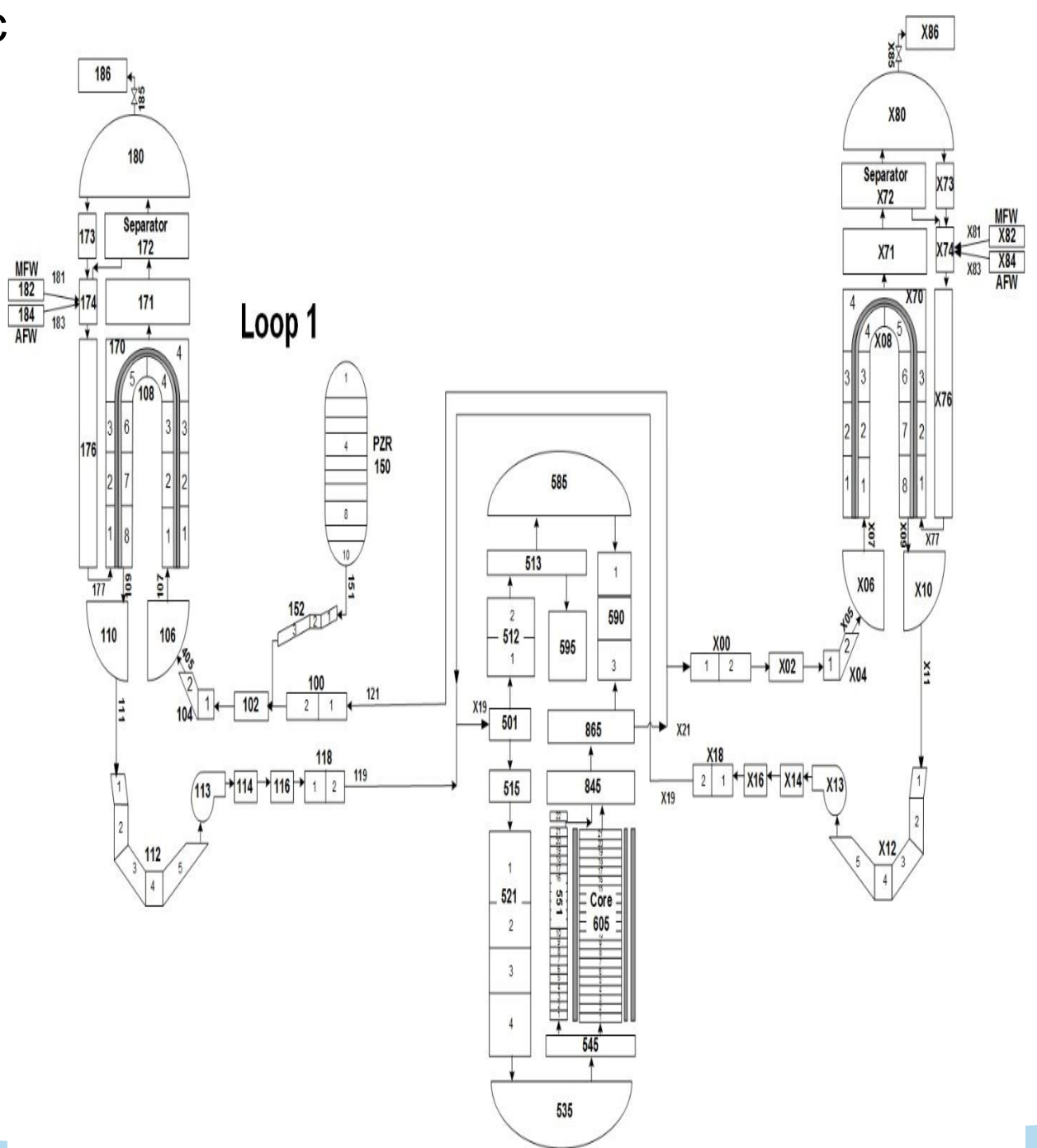




\section{IWRS \\ BEPU Analysis - LOTUS with Baseline Tools (LOTUS-B)}

- LB-LOCA with a double-ended guillotine break in a cold leg

- BEPU analysis: Reduced set of PIRT parameters with high importance

- Automatically mapped parameters from fuel performance and core design

- cladding pre-transient hydrogen up-take contents, rod internal pressure, gap gas mole fraction, power distribution, etc.

- 5 LOCA start times in cycle and maneuver. 1000 Monte Carlo samples for each start time.

Distribution of Parameter Uncertainties

\begin{tabular}{|l|l|l|l|l|}
\hline Parameter & PDF type & Min & Max & Comments \\
\hline Reactor thermal power & Uniform & 1.0 & 1.02 & Multiplier \\
\hline Reactor decay heat power multiplier & Uniform & 0.94 & 1.06 & Multiplier \\
\hline Accumulator pressure (psia) & Normal & 0.9 & 1.1 & Multiplier \\
\hline Accumulator liquid volume $\left(\mathrm{ft}^{3} / \mathrm{m}^{3}\right)$ & Uniform & $-10 /-0.28$ & $10 / 0.28$ & Additive \\
\hline Accumulator temperature (F/K) & Uniform & $-20 /-11.11$ & $30 / 16.67$ & Additive \\
\hline Subcooled multiplier for discharge critical flow & Uniform & 0.8 & 1.2 & Multiplier \\
\hline Two-phase multiplier for discharge critical flow & Uniform & 0.8 & 1.2 & Multiplier \\
\hline $\begin{array}{l}\text { Superheated vapor multiplier for discharge critical } \\
\text { flow }\end{array}$ & Uniform & 0.8 & 1.2 & Multiplier \\
\hline Fuel thermal conductivity & Normal & 0.93 & 1.07 & Multiplier \\
\hline Average core coolant temperature (F/K) & Normal & $-3 /-1.67$ & $3 / 1.67$ & Additive \\
\hline $\begin{array}{l}\text { Turbulent forced convection heat transfer } \\
\text { coefficient }\end{array}$ & Uniform & 0.7 & 1.3 & Multiplier \\
\hline Nucleate boiling heat transfer coefficient & Uniform & 0.7 & 1.3 & Multiplier \\
\hline Multiplier on Critical Heat Flux (CHF) & Uniform & 0.7 & 1.3 & Multiplier \\
\hline $\begin{array}{l}\text { Multiplier on transition boiling heat transfer } \\
\text { coefficient }\end{array}$ & Uniform & 0.7 & 1.3 & Multiplier \\
\hline Film boiling heat transfer coefficient & Uniform & 0.7 & 1.3 & Multiplier \\
\hline Fuel rod gap width & Uniform & 0.2 & 0.8 & Multiplier \\
\hline
\end{tabular}




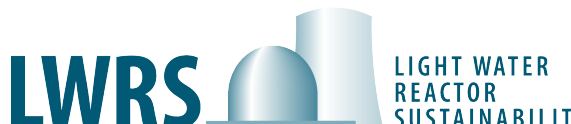

\section{Risk Assessment of LB-LOCA Analyses for the Generic PWR Model Based on STP}

The PCT \& ECR values versus pre-transient cladding hydrogen content for the limiting cases are compared against with proposed acceptance criteria in 10 CFR 50.46c to demonstrate margins.
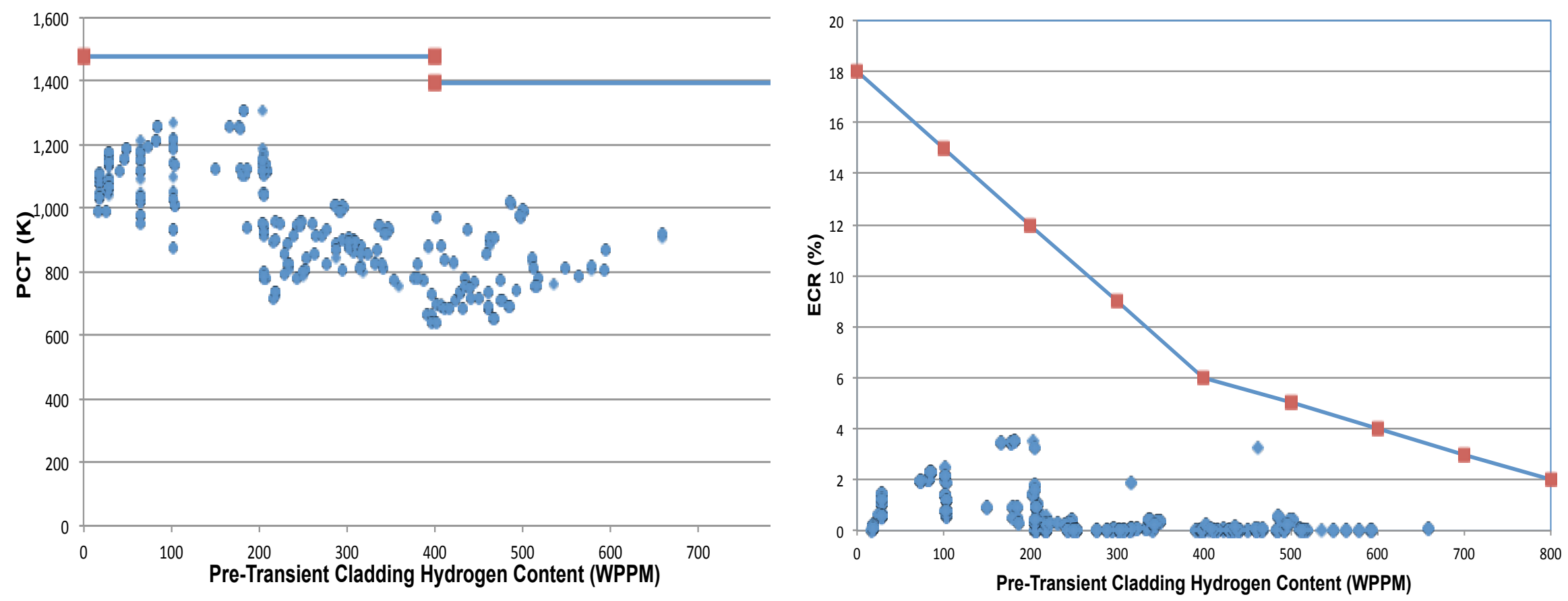

Safety margins have been demonstrated with LOTUS-B analyses. 


\section{Part II}

\section{Integrated Risk Evaluation Model (IREM) \& Risk- Informed Decision Making Applications}


- Utilizing RISMC methods and toolkit to substantially reduce operating costs through risk-informed design changes to the plant, while maintaining high level reactor safety:

- Perform plant- and component-level evaluations of Resilient NPP design concepts (i.e., Accident Tolerant Fuel (ATF), FLEX, new passive cooling systems, core infrastructure etc.)

- Develop a comprehensive Integrated Risk Evaluation Model (IREM) by combining PRA and Multi-Physics Best Estimate Plus Uncertainty methods (the LOTUS toolkit) to reduce conservatisms in risk models and to find associated risk importance.

- Evaluate potential operating cost savings through riskinformed decision making applications. 


\section{Resilient Nuclear Power Plant}

- Accident Tolerant Fuel (ATF) + FLEX + Passive Designs = Resilient NPP

- ATF

- Improved fuel and cladding properties

- Improved clad reaction with steam

- Slower hydrogen generation rate

- Better fission product retention

- Improved fuel cladding interactions

- FLEX: Diverse and Flexible Coping Strategies

- Onsite

- Diesel Generators (4.16kV, 480V)

- Pumps (core cooling, water makeup)

- Offsite Equipment \& Personnel

- Passive Designs

- Passive systems to remove decay heat (e.g. RCIC Extended Op. Band)
Improved Reaction Kinetics with Steam - Heat of oxidation

Improved Fuel Properties

- Lower operation temperatures

- Clad internal oxidation

- Fuel densification/relocation

- Fuel melting

Oxidation rate

Retention of Fission Products - Gaseous fission products

Accident

Tolerant

Fuel

Improved Cladding Properties Slower Hydrogen Generation Rate - Clad fracture

- Dimension stability

- Thermal shock resistance

- Hydrogen bubble

- Clad melting
- Hydrogen explosion - Hydrogen embrittlement of clad 


\section{Resilient NPP Risk Implications}

- Longer available time window for operator actions

- Lower human error probabilities

- Better utilization of the FLEX

- Potential impacts on PRA model by Resilient NPP

- Success Criteria

- Accident Sequence

- Risk reductions on

- Level 1 CDF

- Level 2 LERF

- Impact on risk-informed applications

- 10 CFR 50.69

- SDP, MSPI, NOED...

- RI-TS 4b, 5b...

- RI-EP... 


\section{IWRS (d) \\ Game Changers beyond Delivering the Nuclear Promise}

Source: Scot Greenlee, SVP, Engineering \& Tech Services, Exelon Generation, Nuclear, 2016 ANS Utility Working Conference, Amelia Island

"Risk informing is good business"
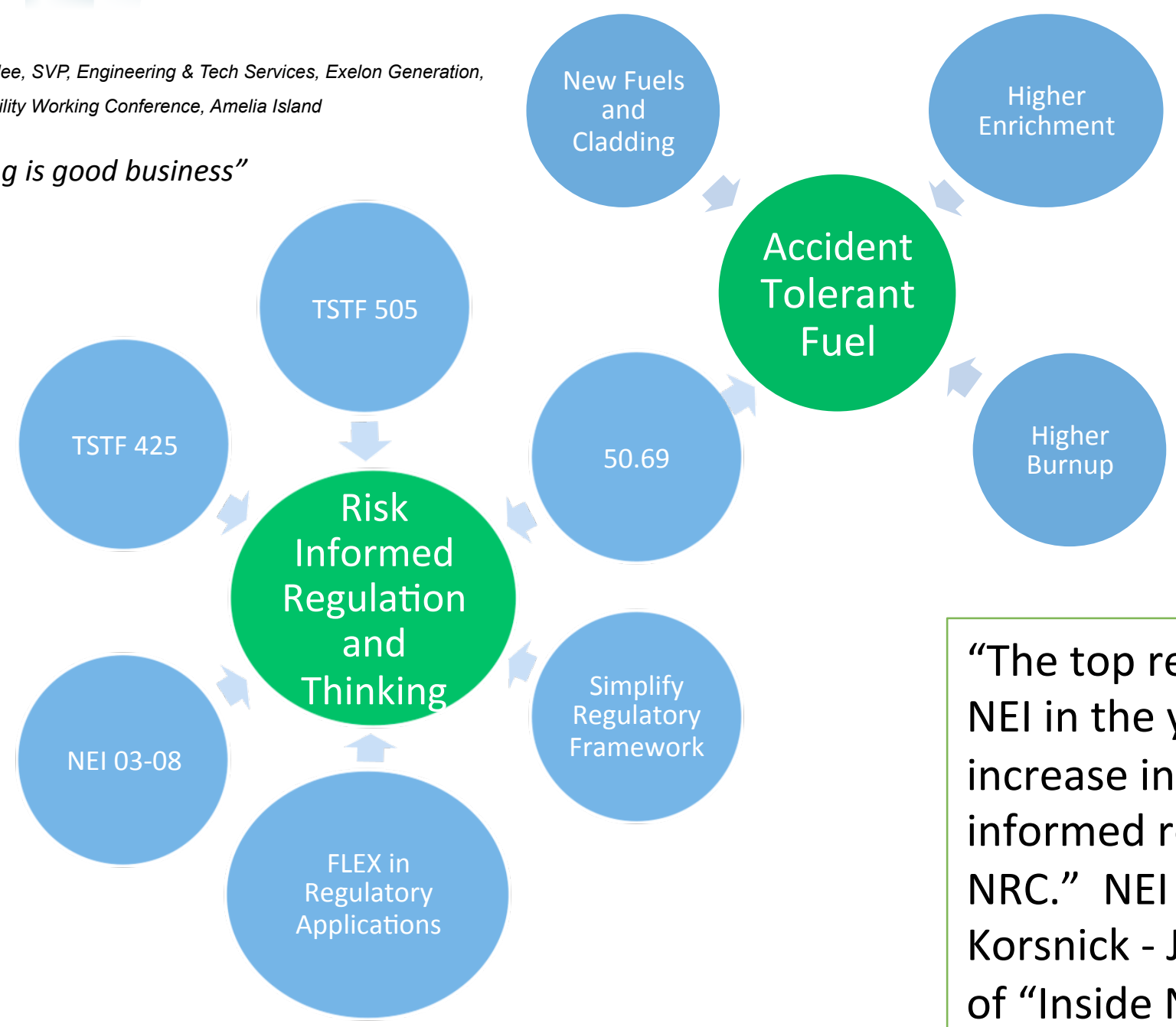

"The top regulatory priority for $\mathrm{NEl}$ in the year ahead is an increase in the use of riskinformed regulation principles by NRC." NEI President \& CEO Maria Korsnick - January 8, 2018, edition of "Inside NRC". 


\section{How Can Resilient NPP help O\&M cost reduction?}

\section{IWPS
LOCA
RIA
DNB
SLB
SBO
DBAs \& BDBAs

Trace accidents to equipment demands and Tech Specs with Resilient NPP

Diesels

Accumulators

Pumps

Safety Valves

Components EOPs

I\&C Protection

FLEX Equipment

\& System

Identify O\&M requirements for that equipment with increased coping time

Surveillance

Repairs

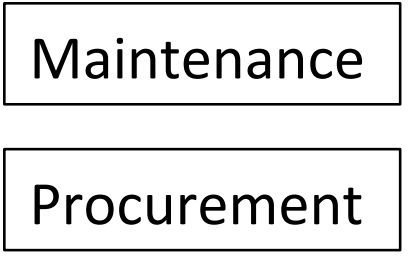

$$
\text { Inspections }
$$

Training
JCO, LCO

$\mathrm{CDBI}$
$O \& M$

Identify cost reduction opportunities with increased coping time O\&M Cost Reduction 


\section{IWIRS \\ Integrated Risk Evaluation Model}

\section{Base Design} Resilient NPP_1 Resilient NPP_2

Resilient NPP_N

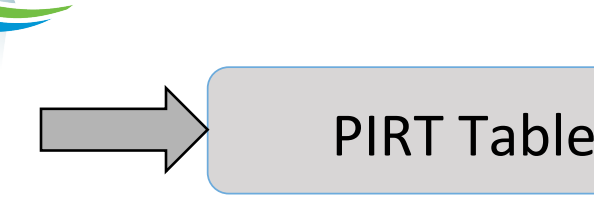

एᄂ

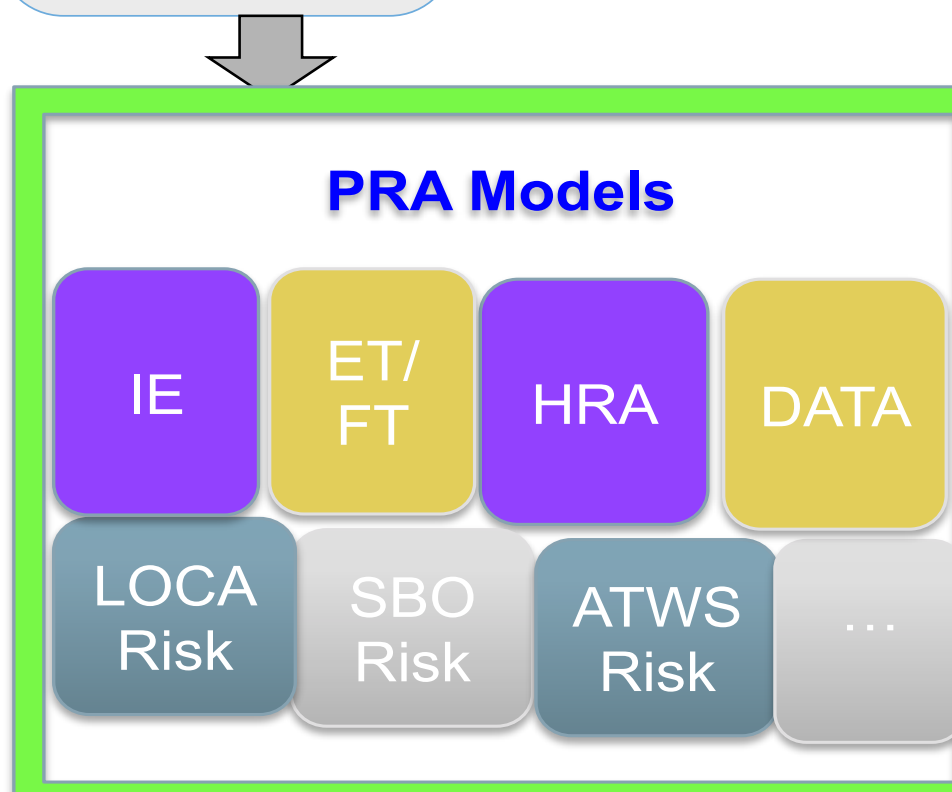
$\mathrm{C}_{\text {LERF }}^{\text {CDF }}$
Stochastic Sampling
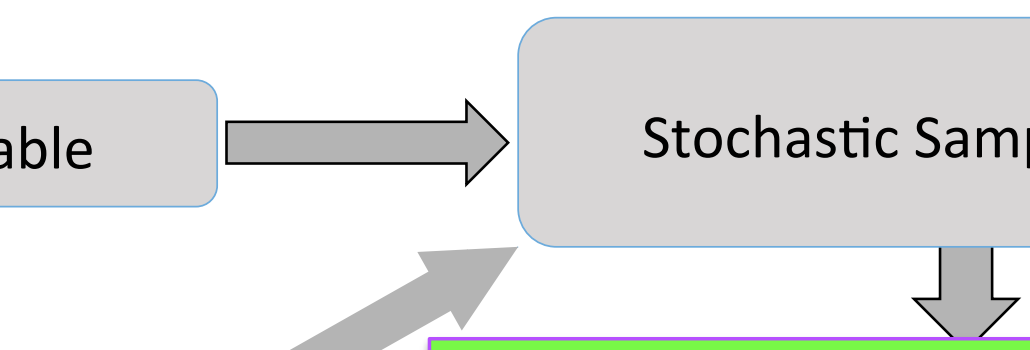

\section{Multi-Physics Best Estimate Plus Uncertainty Simulations}

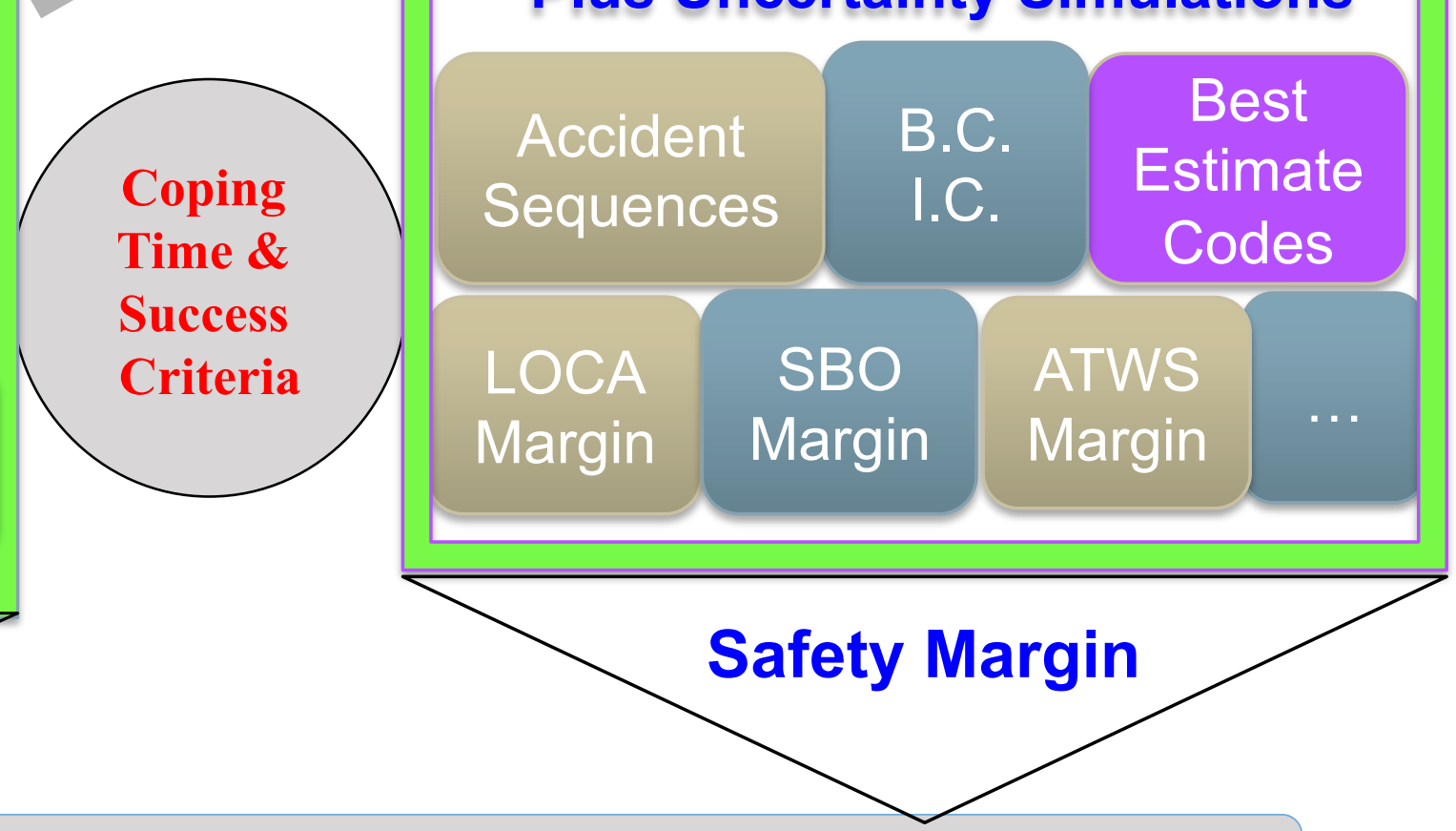

High Value Risk-Informed Decision Making Applications 


\section{LWRS_』}

- Develop a generic PWR PRA model for Station Blackout (SBO).

- Develop Best Estimate plant system and fuel performance models for various ATF concepts. (including BU extension).

- Perform PRA/Best Estimate simulations with scenarios considering FLEX.

- Quantify risk reduction ( $\triangle \mathrm{CDF}$ ) of ATP.

- Investigate risk-informed applications. 


\section{Integrated Risk Assessment}

- Generic SAPHIRE PRA Model

- 3-Loop PWR

- SPAR-level details

- Typical IEs/ETs/FTs

- Industry Average Data

- Best-Estimate

。 RELAP5 Model for a 3-Loop PWR

- Near-Term and Long-Term ATF Designs

- UO2/FeCrAl

- UO2/Cr-Coated Zr

- U3Si2/SiC

- FLEX
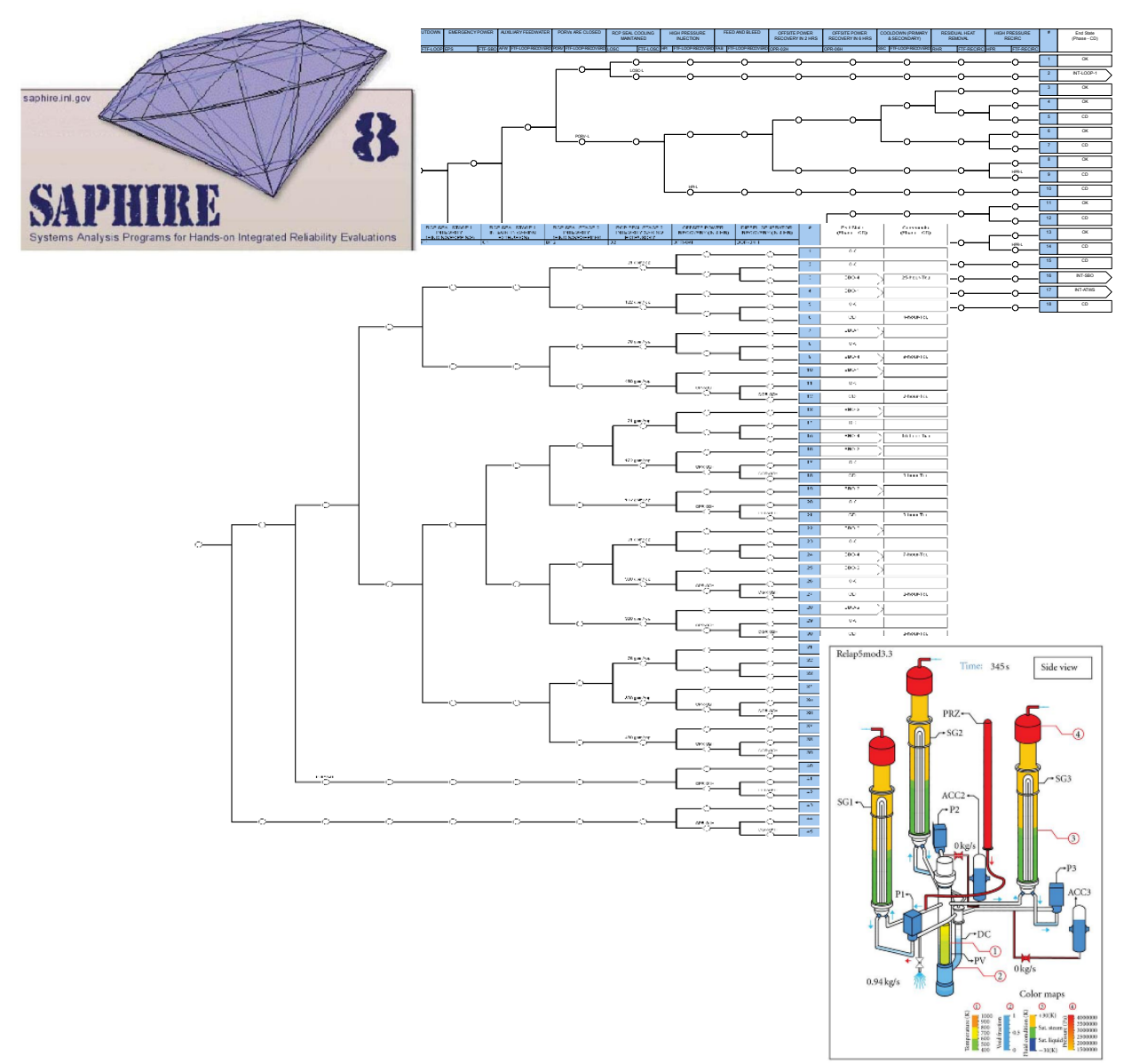


\section{LWRS

Generic PRA SAPHIRE LOOP/SBO Model

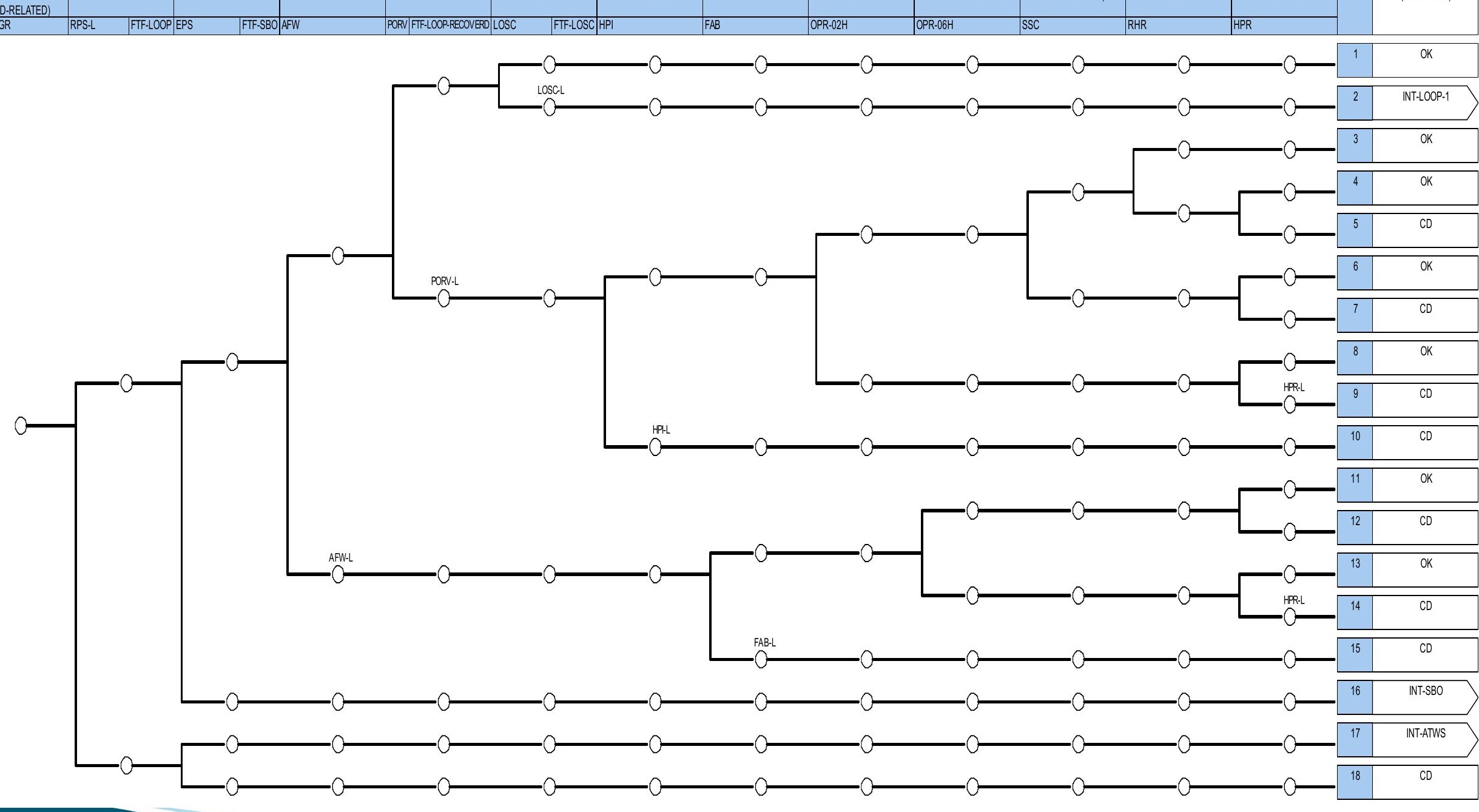





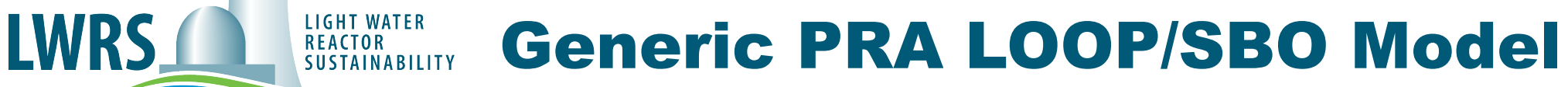

- 4 LOOP event trees corresponding to the 4 LOOP categories

- Grid Related (LOOPGR)

- Plant Centered (LOOPPC)

- Switchyard Centered (LOOPSC)

- Weather Related (LOOPWR)

- Total SBO CDF from all 4 ETs: 8.21E-7/yr

- LOOPGR

- 222 LOOP sequences

- 76 SBO sequences

- 36 non-zero SBO sequences (1E-12 cutoff)

- SubTotal SBO CDF 3.77E-7/yr 


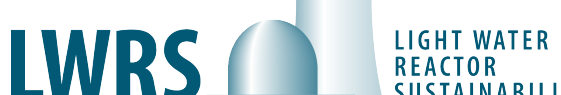 \\ RELAP5-3D Scenarios}

- The 36 non-zero SBO sequences are reviewed and translated to 15 RELAP5-3D scenarios for $\mathrm{T}-\mathrm{H}$ analysis

\begin{tabular}{|c|c|c|c|c|c|c|c|c|}
\hline $\begin{array}{l}\text { RELAP5 } \\
\text { Scenario }\end{array}$ & \multicolumn{8}{|c|}{ Scenario } \\
\hline SBO-1.0 & AFW & PORV Closed & RSD & 21gpm/RCP & $4 \mathrm{Hrs} \mathrm{No}$ & No AFW-MAN & & \\
\hline SBO-1.2 & AFW & PORV Closed & RSD & 21gpm/RCP & $4 \mathrm{Hrs} \mathrm{No}$ & AFW-MAN & No SG Depre. & No Late OPR \\
\hline SBO-2.0 & AFW & PORV Closed & RSD & 76gpm/RCP & $4 \mathrm{Hrs} \mathrm{No}$ & No AFW-MAN & & \\
\hline SBO-2.2 & AFW & PORV Closed & RSD & 76gpm/RCP & 4Hrs No & AFW-MAN & No SG Depre. & No Late OPR \\
\hline SBO-2.3 & AFW & PORV Closed & RSD & 76gpm/RCP & 4Hrs Yes & $\mathrm{HPI}$ & Cooldown & No LPR \\
\hline SBO-3.0 & AFW & PORV Closed & RSD & $182 \mathrm{gpm} / \mathrm{RCP}$ & $4 \mathrm{Hrs} \mathrm{No}$ & & & \\
\hline SBO-3.1 & AFW & PORV Closed & No RSD & $182 \mathrm{gpm} / \mathrm{RCP}$ & $3 \mathrm{Hrs} \mathrm{No}$ & & & \\
\hline SBO-3.3 & AFW & PORV Closed & RSD & $182 \mathrm{gpm} / \mathrm{RCP}$ & 4Hrs Yes & HPI & Cooldown & No LPR \\
\hline SBO-4.0 & AFW & PORV Closed & RSD & 480gpm/RCP & $2 \mathrm{Hrs} \mathrm{No}$ & & & \\
\hline SBO-4.3 & AFW & PORV Closed & RSD & 480gpm/RCP & $2 \mathrm{Hrs}$ Yes & $\mathrm{HPI}$ & Cooldown & No LPR \\
\hline SBO-5.1 & AFW & PORV Closed & No RSD & $300 \mathrm{gpm} / \mathrm{RCP}$ & $2 \mathrm{Hrs} \mathrm{No}$ & & & \\
\hline SBO-6.0 & AFW & PORV Opened & NA & NA & $1 \mathrm{Hr} \mathrm{No}$ & & & \\
\hline SBO-6.3 & AFW & PORV Opened & NA & NA & $1 \mathrm{Hr}$ Yes & $\mathrm{HPI}$ & No HPR & \\
\hline SBO-7.0 & No AFW & NA & NA & NA & $1 \mathrm{Hr} \mathrm{No}$ & & & \\
\hline SBO-7.3 & No AFW & NA & NA & $300 \mathrm{gpm} / \mathrm{RCP}$ & $1 \mathrm{Hr}$ Yes & AFW & No HPI & \\
\hline
\end{tabular}




\section{LWRS A}

- RELAP5-3D base case and ATF case

- Base case with Zr design/ATF case with FeCrAl design

- The time to core damage for ATF would have a gain of about 30 minutes (SBO-1.0, 2.0, and 3.1), no gain (SBO-4.0), or reduction of about 20 minutes (SBO-3.0)

- Two scenarios (SBO-1.2 and 2.2) show no core damage within 24 hrs in both fuel designs

- When considering uncertainty, the difference in the time to core damage between the fuel designs may be minimal for the scenarios analyzed

\begin{tabular}{|c|c|c|c|c|}
\hline RELAP5 Scenario & Description & $t_{0}(Z r)$ & $\mathbf{t}^{\prime}(\mathrm{FeCrAl})$ & $\Delta \mathrm{t}$ \\
\hline SBO-1.0 & 21gpm, 4Hrs No, No AFW-MAN & $10: 47$ & $11: 33$ & $0: 46$ \\
\hline SBO-1.2 & 21gpm, 4Hrs No, AFW-MAN & \multicolumn{2}{|c|}{ No CD in $24 \mathrm{hr}$} & NA \\
\hline SBO-2.0 & 76gpm, 4Hrs No, No AFW-MAN & $10: 30$ & $11: 00$ & $0: 30$ \\
\hline SBO-2.2 & 76gpm, 4Hrs No, AFW-MAN & \multicolumn{2}{|c|}{ No CD in $24 \mathrm{hr}$} & NA \\
\hline SBO-3.0 & 182gpm, 4Hrs No & $10: 54$ & $10: 35$ & $-0: 19$ \\
\hline SBO-3.1 & 182gpm, No RSD, 3Hrs No & $7: 22$ & 7:48 & $0: 26$ \\
\hline SBO-4.0 & 480gpm, 2Hrs No & $5: 42$ & $5: 44$ & $0: 02$ \\
\hline
\end{tabular}




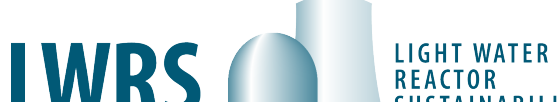 \\ Preliminary Results}

- SBO-1.0, 2.0 (gain of 30 minutes)

- Assume the gain of 30 minutes would reduce the human error probability

- $\triangle \mathrm{CDF}=-2.64 \mathrm{E}-8 / \mathrm{yr}$

- SBO-3.0 (reduction of 20 minutes), SBO-3.1 (gain of 30 minutes),

- The differences in the time to core damage do not warrant a change in PRA model on required time to recover offsite power

- $\triangle \mathrm{CDF}=0$

- SBO-4.0 (same timing), SBO-1.2, 2.2 (no core damage in both designs)

- $\triangle \mathrm{CDF}=0$

- Total CDF change

- $\triangle \mathrm{CDF}=-2.64 \mathrm{E}-8 / \mathrm{yr}$, about $-9 \%$ of $2.94 \mathrm{E}-7 / \mathrm{yr}$

\begin{tabular}{|c|c|c|c|c|c|c|c|}
\hline RELAP5 Scenario & Description & $t_{0}(\mathrm{Zr})$ & $\mathbf{t}^{\prime}(\mathrm{FeCrAI})$ & $\Delta \mathrm{t}$ & $\mathrm{CDF}_{0}$ & CDF' & $\triangle \mathrm{CDF}$ \\
\hline SBO-1.0 & 21gpm, 4Hrs No, No AFW-MAN & $10: 47$ & $11: 33$ & $0: 46$ & $1.57 \mathrm{E}-07$ & $1.31 \mathrm{E}-07$ & $-2.61 \mathrm{E}-08$ \\
\hline SBO-1.2 & 21gpm, 4Hrs No, AFW-MAN & \multicolumn{2}{|c|}{ No CD in $24 \mathrm{hr}$} & NA & $2.23 \mathrm{E}-09$ & 2.23E-09 & $0.00 E+00$ \\
\hline SBO-2.0 & 76gpm, 4Hrs No, No AFW-MAN & $10: 30$ & $11: 00$ & $0: 30$ & 1.91E-09 & 1.59E-09 & $-3.18 \mathrm{E}-10$ \\
\hline SBO-2.2 & 76gpm, 4Hrs No, AFW-MAN & \multicolumn{2}{|c|}{ No CD in $24 \mathrm{hr}$} & NA & 7.35E-10 & $7.35 \mathrm{E}-10$ & $0.00 \mathrm{E}+00$ \\
\hline SBO-3.0 & $182 \mathrm{gpm}, 4 \mathrm{Hrs} \mathrm{No}$ & $10: 54$ & $10: 35$ & $-0: 19$ & $1.30 \mathrm{E}-07$ & $1.30 \mathrm{E}-07$ & $0.00 E+00$ \\
\hline SBO-3.1 & 182gpm, No RSD, 3Hrs No & $7: 22$ & $7: 48$ & $0: 26$ & $5.84 \mathrm{E}-10$ & $5.84 \mathrm{E}-10$ & $0.00 \mathrm{E}+00$ \\
\hline SBO-4.0 & 480gpm, $2 \mathrm{Hrs} \mathrm{No}$ & $5: 42$ & $5: 44$ & 0:02 & 4.37E-09 & 4.37E-09 & $0.00 E+00$ \\
\hline Total & & & & & $2.94 \mathrm{E}-07$ & $2.70 \mathrm{E}-07$ & $-2.64 \mathrm{E}-08$ \\
\hline
\end{tabular}




\section{LWRSAN}

- Expand the generic PWR PRA model to other scenarios - LOCA, ATWS, LOFW, SGTR, etc.

- Develop Best Estimate Plus Uncertainty plant system and fuel performance calculations with ATF/ATP for expanded scenarios and on LERF level.

- Perform PRA/Best Estimate simulations with scenarios considering FLEX with LERF as the risk metric.

- Start the model development (PRA and Best Estimate) for BWRs

- Quantify risk reduction of ATP with $\triangle \mathrm{CDF}$ and $\triangle \mathrm{LERF}$. 


\section{LWRS A Collaboration Discussions}

- Resilient Plant Systems

- Margin recapture/recovery

- FLEX Applications

- Costs/benefits analysis

- Risk-Informed Decision Making Applications

- Enhanced fuel performance (enrichment / burnup / load follow)

- Risk-informed surveillance test intervals

- Risk Managed Technical Specifications

- 10 CFR 50.69 alternative treatments

- Emergency Preparedness enhancements (e.g. longer response)

- JCO - Justification for continued operation

- LCO - Limiting condition for operation

- $\mathrm{CDBI}$ - Component design bases inspection

- SDP - Significance determination process

- MSPI - Mitigating Systems Performance Index

- NOED - Notice of Enforcement Discretion 


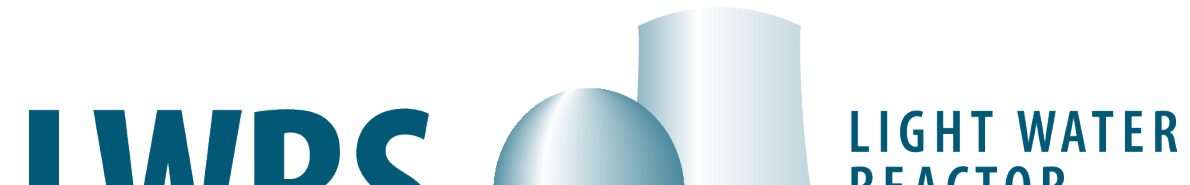 REACTOR \\ SUSTAINABILITY \\ Sustaining Mational Muclear flssets
}

\author{
http://lwrs.inl.gov
}

